\title{
Selective Targeting of Different Neural Cell Adhesion Molecule Isoforms during Motoneuron-Myotube Synapse Formation in Culture and the Switch from an Immature to Mature Form of Synaptic Vesicle Cycling
}

\author{
Katsusuke Hata, Luis Polo-Parada, and Lynn T. Landmesser \\ Department of Neurosciences, Case Western Reserve University, School of Medicine, Cleveland, Ohio 44106-4975
}

\begin{abstract}
Characterization of neuromuscular junction formation and function in mice lacking all neural cell adhesion molecule (NCAM) isoforms or only the 180 isoform demonstrated that the 180 isoform was required at adult synapses to maintain effective transmission with repetitive stimulation whereas the 140 and/or 120 isoform(s) were sufficient to mediate the downregulation of synaptic vesicle cycling along the axon after synapse formation. However, the expression and targeting of each isoform and its relationship to distinct forms of synaptic vesicle cycling before and after synapse formation was previously unknown. By transfecting chick motoneurons with fluorescently tagged mouse 180, 140 and 120 isoforms, we show that before myotube contact the 180 and 140 isoforms are expressed in distinct puncta along the axon which are sites of an immature form (Brefeldin A sensitive, $\mathrm{L}-\mathrm{type} \mathrm{Ca}^{2+}$ channel mediated) of vesicle cycling. After myotube contact the 140 and 180 isoforms are downregulated from the axon and selectively targeted to the presynaptic terminal. This coincided with the downregulation of vesicle cycling along the axon and the expression of the mature form (BFA insensitive, $P / Q$ type $\mathrm{Ca}^{2+}$ channel mediated) of vesicle cycling at the terminal. The synaptic targeting of exogenously expressed 180 and 140 isoforms also occurred when chick motoneurons contacted $+/+$ mouse myotubes; however only the 180 but not the 140 isoform was targeted on contact with $\mathrm{NCAM}^{-1-}$ myotubes. These observations indicate that postsynaptic NCAM is required for the synaptic targeting of presynaptic 140 NCAM but that the localization of presynaptic 180 NCAM occurs via a different mechanism.
\end{abstract}

Key words: NCAM; synaptic vesicle cycling; presynaptic differentiation; neuromuscular junction formation; adhesion molecule targeting; calcium channels

\section{Introduction}

The neural cell adhesion molecule (NCAM) mediates a variety of cell-cell interactions that are important for different aspects of neural development including cell migration, axon outgrowth/ pathfinding, and synapse formation. In addition, NCAM also modulates plastic changes in the adult nervous system including long-term potentiation. Although some of these effects may be attributable to NCAM acting as a cell adhesion molecule, others result from intracellular signaling pathways activated by NCAM (for review, see Crossin and Krushel, 2000; Kiss and Muller, 2001; Rougon and Hobert, 2003).

NCAM has three major alternatively spliced isoforms (Cun-

Received April 16, 2007; revised 0ct. 31, 2007; accepted Nov. 21, 2007.

This work was supported by National Institutes of Health Grants NS19640 and NS23678 from National Institute of Neurological Disorders and Stroke and by American Heart Association Grant 0530140. We thank Katherine Lobur for her technical assistance, Dr. Yuka Maeno-Hikichi for her input throughout the experiments, and Dr. Susann BradyKalnay for critical reading of this manuscript. We also thank Dr. Samuel Pfaff for the HB9 antibody.

Correspondence should be addressed to Lynn T. Landmesser. Department of Neurosciences, Case Western Reserve University, 10900 Euclid Avenue, Cleveland, 0H 44106-4975. E-mail: lynn.landmesser@case.edu.

L. Polo-Parada's present address: Dalton Cardiovascular Research Center, University of Missouri, Columbia, M0 65211.

D0I:10.1523/JNEUROSCI.3847-07.2007

Copyright $\odot 2007$ Society for Neuroscience 0270-6474/07/2714481-13\$15.00/0 ningham et al., 1987; Barbas et al., 1988): the 140 and 180 isoforms have intracellular domains differing only by a 267 amino acid insert in the 180 isoform, whereas the 120 isoform is GPIlinked and lacks an intracellular domain (see Fig. 1A). Many NCAM antibodies are not useful for localizing the different isoforms because they are directed against the extracellular domains, which are highly conserved. Similarly although 180 isoformspecific antibodies exist (Schlosshauer, 1989), the distribution of each isoform within the axon during motor axon outgrowth and synapse formation has not been previously characterized.

Adult mice lacking all three isoforms are unable to maintain effective neuromuscular transmission with repetitive stimulation. These mice also maintain an immature form of synaptic vesicle cycling along axons that is Brefeldin A sensitive and uses calcium that enters through L-type channels (Polo-Parada et al., 2001). Immature Xenopus motoneurons are capable of stimulus evoked exocytosis and release of transmitter along axons and from growth cones (Sun and Poo, 1987; Dai and Peng, 1996; Zakharenko et al., 1999), but after myotube contact synaptic vesicle cycling along axons is downregulated (Chow and Poo, 1985). However the molecules mediating this downregulation and whether it requires a signal from the myotube or is simply a consequence of motoneuron maturation has remained unclear 
(Chow and Poo, 1985; Antonov et al., 1999). Recent studies have shown that mice lacking only the 180 isoform of NCAM continue to exhibit transmission failures with repetitive stimulation (PoloParada et al., 2004, 2005); however the immature form of vesicle cycling along axons was downregulated, implying that either the 140 or 120 NCAM isoforms are involved in this process.

By expressing fluorescently tagged mouse isoforms in chick motoneurons, we show here that before myotube contact the 180 and 140 isoforms are colocalized in puncta long the axon that are sites of immature vesicle cycling. On myotube contact the 180 and 140 isoforms are selectively targeted to the presynaptic terminal, coinciding with the downregulation of vesicle cycling along the axon. Selective synaptic targeting of the exogenously expressed 180 and 140 isoforms also occurred when chick motoneurons contacted $+/+$ mouse myotubes. However, on contact with $\mathrm{NCAM}^{-1-}$ myotubes, only the 180 but not the 140 isoform was selectively targeted. These results thus demonstrate differences in the mechanism of targeting between the two isoforms and a role for postsynaptic NCAM in presynaptic 140isoform targeting.

\section{Materials and Methods}

Development of fluorescently tagged NCAM isoform constructs. Full-length murine NCAM cDNAs (Hartmann et al., 1994) were used as templates for high-fidelity PCR. Briefly, the complete coding sequence of each NCAMs (180, 140, and $120 \mathrm{kDa}$ isoform) was amplified by Advantage-HF 2 PCR kit (Advantage-HF2 PCR kit, K1914-1; BD Biosciences, San Jose, CA) using the 5' PCR primer (5'- CCCAAGCTTATGCTGCGAACTAAGGATCTC- $3^{\prime}$ ) corresponding to a mouse $\mathrm{N}$-terminal NCAM sequence following the unique HindIII restriction site, and the 3' PCR primer (5'-AAATCTAGATCATGCTTTGCTCTCATTCTC-3' for NCAMs 180 and 140, 5'-AAATCTAGATCAGAGCAGAAGAAGAGTCACCGC-3' for NCAM 120, or 5'-AAATCTAGATCAATCGTTGGGGACCGTCTTGAC- $3^{\prime}$ for KENESKA-truncated NCAMs), codes for the complementary sequence to the C-terminal amino acids of NCAMs, followed by the termination codon and unique $X b a \mathrm{I}$ restriction sites. The amplified NCAM products were gel-purified, digested with HindIII and XbaI, and then cloned into HindIII/XbaI-cut pcDNA3. $1^{+}$vector (Clontech, Mountain View, CA).

FP (fluorescent protein)-NCAM chimera were constructed by introducing Sbfl sites at the $5^{\prime}$ and $3^{\prime}$ ends of the coding sequence of the eCFP, eYFP, mRFP and eGFP cDNA using the primers (5'-AAAATCCCTGCAGGTAATGGTGAGCAAGGGCGAG-3' and 5'-AAAATACCTGCAGGTACTTGTACAGCTCGTCCAT-3' for eCFP, eYFP and eGFP, 5' AAAATCCCTGCAGGTAATGGCCTCCTCCGAGGAC- $3^{\prime}$ and $5^{\prime}$ AAAATACCTGCAGGGCGCCGGTGGAGTGGCGGCCCTC-3' for mRFP) by standard PCR technique. Because mRFP has one Sbfl site, silent mutation was introduced in this position in advance. Then these FP fragments were cloned into the unique Sbfl site (position 57, between the end of signal peptide and the first Ig-like domain) of a HindIII/XbaI subfragment of NCAMs. Sequence accuracy and the direction of the FP insertion were verified by DNA-sequencing. The HindIII/XbaI subfragment was cloned into the pcDNA3.1 $1^{+}$vector, which contained the $5^{\prime}$ HindIII/XbaI fragment of NCAMs. Expression of NCAM was driven by the CMV promoter which is contained in pcDNA3. $1^{+}$.

Western blotting. COS-7 cells were grown to $95 \%$ confluence in DMEM $+10 \%$ FBS in a $5 \% \mathrm{CO}_{2}$ incubator, then transfected with the indicated plasmid $(2 \mu \mathrm{g} / \mathrm{ml})$ with transfectin reagent $(2 \mu \mathrm{l} / \mathrm{ml}$; Bio-Rad, Hercules, CA) following the manufacturer's recommendation method. After $48 \mathrm{~h}$, cells were lysed by SDS-sample buffer, and the proteins were separated by SDS-PAGE according to the Laemli's method on a $4-15 \%$ gradient gel. The proteins were transferred onto polyvinylidene fluoride membranes which were immunostained with monoclonal anti-mouse NCAM antibody (NCAM13) which recognizes all three NCAM isoforms and appropriate HRP-conjugated secondary antibody, which was visualized with a chemiluminescence kit (ECL; Pierce, Rockford, IL).

Cell aggregation assay. COS-7 cells were cultured in T25-culture flasks at a $70 \%$ confluent state, then transfected with individual NCAM isoform plasmids as described below. After $24 \mathrm{~h}$, the cells were removed from the substrate by $2 \mathrm{~mm}$ EDTA/PBS, adjusted to a density of $1 \times 10^{7}$ cells/ml by PBS, and incubated at $37^{\circ} \mathrm{C}$ for $40 \mathrm{~min}$ in $1.5 \mathrm{ml}$ tubes. The tubes were then rotated slowly four-times, and the number of all cells and those that were not in aggregates but individually dispersed were counted in eight fields in a hemocytometer, and the per cent of cells in aggregates calculated.

Culture and electroporation with NCAM constructs of chick spinal motoneurons, and myotubes. Motoneurons were obtained from stage (St.) 25 chick lumbar spinal cord, because motoneurons have not contacted myotubes at this time, and were prepared as dissociated cells or as explants. For dissociated cell culture, the ventrolateral portion of the lumbar spinal cord was dissected in oxygenated Tyrode's solution from embryos after a ventral laminectomy and treated with $0.25 \%$ trypsin for 30 min at $37^{\circ} \mathrm{C}$. After washing one time with DMEM-10\%FBS (DMEM10) and three times with HBSS, the cords were triturated with a series of fire-polished Pasteur pipettes until the cells were dispersed. After centrifugation at $2000 \mathrm{rpm}$ for $5 \mathrm{~min}$, cells were dissociated in low $\mathrm{Ca}^{2+}(0.5$ $\mathrm{mm}) / \mathrm{high} \mathrm{Mg}^{2+}(12 \mathrm{~mm})$ Tyrode's at a cell density of $2.5 \times 10^{7} / \mathrm{ml}$, and subsequently $100 \mu \mathrm{l}$ of the solution was transferred into electroporator cuvettes (model 640, BTX). $3 \mu \mathrm{g}$ of plasmid (one or more of the fluorescently tagged NCAM isoforms) was added to each cuvette, and the cells were electroporated using the protocol of $400 \mathrm{~V}, 5 \mathrm{~mA}, 1$ pulse via an ECM830 electroporator (BTX; Harvard Apparatus, Holliston, MA). Electroporated cells were immediately dispersed in $2 \mathrm{ml}$ of Neurobasal medium containing $1 \mathrm{ng} / \mathrm{ml}$ each of BDNF, GDNF and CNTF and plated onto four collagen-coated $35 \mathrm{~mm}$ culture dishes for cultures of neurons alone.

For explant cultures, ventral laminectomies were performed on St. 25 chick embryos in oxygenated low $\mathrm{Ca}^{2+}$ Tyrode's solution $(0.5 \mathrm{~mm})$ and $\sim 0.5 \mu \mathrm{l}$ of NCAM plasmids $(5 \mu \mathrm{g} / \mu \mathrm{l})$ were injected via a micropipette directly into the lumbar ventral spinal cord, which was then electroporated using the protocol of $25 \mathrm{~V}, 50 \mathrm{~mA}, 5$ pulses, 2 times (Bonnot et al., 2005). The cords were collected, and the ventrolateral portions cut into $0.1 \mathrm{~mm}$ cubes. These explants in $300-500 \mu \mathrm{l}$ of medium were either placed onto collagen under the same culture conditions as for the dissociated cells described above for isolated explant cultures, or onto myotube cultures, as described below, for motoneuron-myotube cocultures. After attachment of the explants, $1.5 \mathrm{ml}$ of fresh medium was added.

Based on previous studies from this laboratory, the dissection of the ventrolateral region of St. 25 lumbar cords was known to yield cultures highly enriched in motoneurons. However to confirm this finding, dissociated cell cultures were stained with antibodies to HB9, a transcription factor selectively expressed in motoneurons and a small group of interneurons, and choline acetyltransferase (ChAT) to identify cholinergic neurons after $3 \mathrm{~d}$ in culture. Because no cholinergic interneurons are present at this stage of development in the lumbar cord, ChAT staining is selective for motoneurons. We found that $>90 \%$ of all cells dissociated from such cord dissections were positive for both of these markers (see also Fig. 3). Most of the cells not expressing these markers had the morphology of fibroblasts. Thus all of the data presented in this study is from motoneurons.

To prepare chick myotube cultures, secondary myoblasts were harvested from St. 37-38 chick embryo pectoral muscles and the cells were diluted to $10^{6}$ cells/ml with $2 \mathrm{ml}$ of DMEM/F12 medium containing $10 \%$ horse serum and $5 \%$ chick embryo extract, and $2 \mathrm{ml}$ of solution placed onto collagen-coated round glass coverslips within $35 \mathrm{~mm}$ dishes. On day 3 the medium was replaced with Neurobasal medium containing B27 supplement and Glutamax (1:100), after which myoblasts fused to form myotubes over the next $3 \mathrm{~d}$. For longer term cultures ( $5 \mathrm{~d}$ or more), 1 $\mu \mathrm{g} / \mathrm{ml}$ Ara-C was added on day $2-3$ to kill fibroblasts. In some cases the myotubes were transfected with the NCAM plasmids using Fugene-HD transfection reagent (Roche Diagnostics, Indianapolis, IN).

To prepare mouse myotube cultures the purification and differentiation of myoblasts from wild type (C57BL/6) and NCAM deficient (PoloParada et al., 2001) mice were performed according to the method of Rando and Blau (1994). Differentiated mouse myotubes were cultured for $7 \mathrm{~d}$ with St. 25 chick lumbar ventral spinal cord explants that had been 
A eCFP-NCAM180
eYFP-NCAM140 MRFP-NCAM120

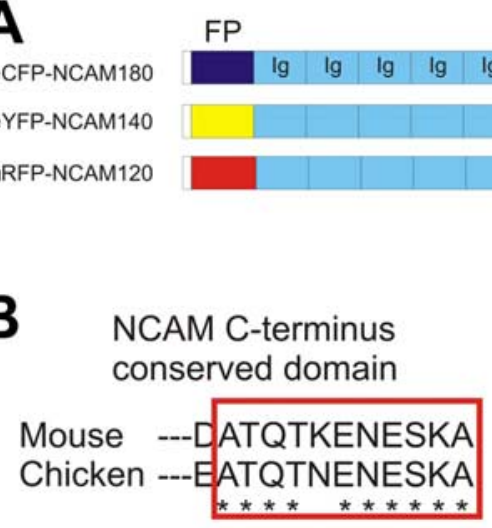

B

for $10 \mathrm{~min}$. Sulfrhodamine (50 $\mu \mathrm{M}$; Invitrogen) was added before assessing dye uptake to quench the surface-bound FM1-43 signal (Pyle et al., 1999). The ability of a subsequent depolarization with $\mathrm{K}^{+}$to release the dye was performed in some cases. All imaging experiments were performed at room temperature. In some cases the characteristics of high $\mathrm{K}^{+}$evoked FM1-43 dye uptake and release were determined for dissociated motoneurons with results similar to the explant cultures. However, all FM1-43 data presented here was from explant cultures.

Image acquisition and data analysis. Basic techniques for imaging FM1-43 loading and unloading were described previously (Polo-Parada et al., 2001). An Olympus Optical (Tokyo, Japan) fluorescence microscope was used and images were acquired with a CCD camera (Retiga Exi; QImaging, Burnaby, British Columbia, Canada) driven by QCapture (Quantitative Imaging) imaging software. Quantification of data were performed using MetaMorph image analysis software. Montages of the images were created using Adobe Photoshop CS2 (Adobe Systems, San Jose, CA).

Cultures were visualized with a $60 \times$ waterimmersion lens and the appropriate filter cubes. All Images were captured at an exposure time of $1.6 \mathrm{~s}$, and background was subtracted. The distribution of fluorescence intensity along the axon and contact site was obtained by drawing a line from the tip of the growth cone or contact site proximally along the center of axon. Puncta of NCAM isoforms and FM1-43 were defined as

electroporated as described above with mRFP tagged NCAM 180 or 140 mouse constructs. Cultures were fixed and the localization of each NCAM isoform quantified.

Immunostaining. Cells were fixed in 3.7\% formaldehyde/PBS for 15 min, treated with $0.1 \%$ Triton X-100 in PBS for 5 min, blocked with $2 \%$ BSA/PBS and treated with a monoclonal antibody specific for chick 180 NCAM (4D; $1 \mu \mathrm{g} / \mathrm{ml})$, a pan-NCAM Ab that recognizes all isoforms of chick NCAM (5E; $10 \mu \mathrm{g} / \mathrm{ml}$ ), anti-syntaxin (S-0664; 1:2000; Sigma, St. Louis, MO) or anti-SNAP25 (S5187; 1:1000; Sigma) for $2 \mathrm{~h}$, then treated with Cy2-conjugated secondary IgG (1:100; Jackson ImmunoResearch, West Grove, PA) or FITC-conjugated IgG (1:500; Zymed Laboratories, South San Francisco, CA) for 2 h, and mounted in Prolong-Gold (Invitrogen, Carlsbad, CA). In other cases cultures were stained with antibodies that recognized HB9 (a gift from Dr. Samuel Pfaff of the Salk Institute, La Jolla, CA) or ChAT (AB 144; Chemicon, Temecula, CA).

FM1-43 dye uptake and characterization of sites of synaptic vesicle cycling. To characterize sites of functional synaptic transmission and vesicle cycling at contacts between motoneurons and myotubes at different times during coculture, the explants were stimulated via a large diameter tip microelectrode pipette filled with culture medium with pulses of $2 \mathrm{~ms}$ duration. Images were acquired to determine the myotubes in which contraction was induced by this procedure so that contacts that mediated effective transmission could be compared with those that did not. Subsequently FM1-43 uptake was characterized. The culture medium was first replaced with a solution containing (in $\mathrm{mm}$ ) $\mathrm{NaCl}, 139 ; \mathrm{KCl}, 3$; $\mathrm{CaCl}_{2}, 3 ; \mathrm{MgCl}_{2}, 1$; dextrose, 12.2; $\mathrm{NaHCO}_{3}, 17$; with or without 10 $\mu \mathrm{g} / \mathrm{ml}$ Brefeldin A (BFA) or calcium channel blockers (L-type, $5 \mu \mathrm{M}$ nifedipine; $\mathrm{N}$-type, $1 \mu \mathrm{M} \omega$-conotoxin GVIA; P/Q-type, $1 \mu \mathrm{M} \omega$-agatoxin $\mathrm{TK}, 2 \mathrm{mM} \mathrm{CoCl}_{2}$ which at this concentration blocks all $\mathrm{Ca}^{2+}$ channels) (Sundgren-Andersson and Johansson, 1998) and allowed to equilibrate for $30 \mathrm{~min}$. Phase contrast pictures were acquired of contact sites or neurites either in contact or not with myotubes. The medium was changed to one containing high- $\mathrm{K}^{+}$Tyrode's solution ( $55 \mathrm{~mm} \mathrm{KCl}$, with a compensatory decrease in $\mathrm{NaCl}$ to $75 \mathrm{mM}$ ) supplemented with $10 \mu \mathrm{M}$ FM1-43 (Invitrogen) for $2 \mathrm{~min}$. and then washed with low $\mathrm{Ca}^{2+} /$ high $\mathrm{Mg}^{2+}$ Tyrode's solution $\left(\mathrm{CaCl}_{2}, 0.5 ; \mathrm{MgCl}_{2} 12\right)$ via $800 \mu \mathrm{l} / \mathrm{min}$ perfusion regions in which the mean pixel intensity of the spot (region of interest) was at least twice the average pixel intensity of the axon (for example, see Fig. 7A). The distribution of such puncta at different distances from the distal tip was then determined. In other cases the mean pixel intensity of the contact site/growth cone was compared with that of the $100 \mu \mathrm{m}$ length of the proximal axon. Quantification for colocalization of NCAM180/NCAM140 was performed using the plasmid of eCFPNCAM180 and mRFP-NCAM140. Colocalization of NCAM180 or NCAM140 and FM1-43 was performed using eCFP-NCAM180 to minimize overlap with the FM1-43 emission. Because only those puncta that were greater than twice the average pixel intensity for the axon were counted as positive puncta for either NCAM or FM1-43, the data presented underestimate the degree of puncta that are positive for both. FM-dye with high $\mathrm{K}^{+}$(no drugs) was normalized to 100, and used as a control.

Statistical analysis. Throughout the text, the data are presented as mean \pm SEM with a two-tailed $t$ test performed to evaluate statistical significance.

\section{Results}

Creation and characterization of fluorescently tagged NCAM isoform constructs

Tagged isoform constructs were created by introducing the coding sequence of either eGFP, eCFP, eYFP or mRFP onto the $\mathrm{N}$-terminal portion of constructs of each of the three major mouse NCAM isoforms (180, 140, and $120 \mathrm{kDa})$ between the signal peptide and the first Ig domain (Fig. 1A) (for additional details, see Materials and Methods). We chose to tag the NCAM protein in the extracellular region so as to not interfere with signaling/protein-protein interactions mediated by the intracellular domain. We have previously (Polo-Parada et al., 2005) identified the highly conserved, intracellular C-terminal KENESKA domain (Fig. $1 \mathrm{~B}$ ), as playing an important role in maintaining 
effective transmission at adult mouse neuromuscular junctions (NMJs).

COS-7 cells, which do not express endogenous NCAM, were transfected with each of these constructs. Western blots of these lysates, stained by NCAM13 antibody that recognizes all isoforms of NCAM (Polo-Parada et al., 2004), showed proteins of the predicted increase in molecular weight compared with the untagged protein (Fig. 1C). Each of the constructs (Fig. $2 \mathrm{~A}$ shows the 140 isoform tagged with mRFP as an example) was visualized with fluorescent microscopy and the distribution of the fluorescent protein was found to be similar to that of NCAM visualized by immunostaining with the pan-NCAM antibody (Fig. $2 \mathrm{~A}$, arrowheads). COS-7 cells do not express endogenous NCAM and do not aggregate when cultured as described in the methods. However when each of the constructs, either untagged or tagged with one of the fluorescent proteins, was expressed, this resulted in robust aggregation of the cells (Fig. $2 B$ ). Thus the proteins tagged on the extracellular domain are still capable of mediating adhesive interactions between cells and thus cell aggregation (for additional details, see Materials and Methods).

Targeting of the exogenously expressed $180 \mathrm{kDa}$ isoform in motoneurons grown alone is similar to the endogenous 180 isoform and does not depend on the KENESKA domain

To characterize the distribution of NCAM isoforms, the fluorescently tagged mouse constructs were expressed in St. 25 chick motoneurons via electroporation of isolated spinal cord-hindlimb preparations in low $\mathrm{Ca}^{2+}$ Tyrode's solution after a ventral laminectomy to expose the ventral cord. The ventrolateral regions of the lumbar cord were dissected and used for either explant or dissociated cell culture. At this stage of development the dissected regions contain predominantly motoneurons, which was confirmed by immunostaining the dissociated cells with antibodies to choline acetyltransferase (ChAT) or the transcription factor HB9, two motoneuronspecific markers. We found that $92.7 \pm$ $3.6 \%$ were ChAT positive, and $90.0 \pm 2.9 \%$ were positive for HB9 (Fig. 3, white arrowheads). The few cells not expressing these markers had non-neuronal morphologies (two cells with dark arrowheads in ChAT immunostained culture)

Because our long term goal is to use exogenously expressed NCAM isoforms to rescue phenotypes in mice lacking all or only the 180 isoform of NCAM, it was important to first demonstrate that the exogenously expressed proteins are targeted appropriately. To better determine the extent to which the tagged isoforms

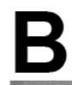

C

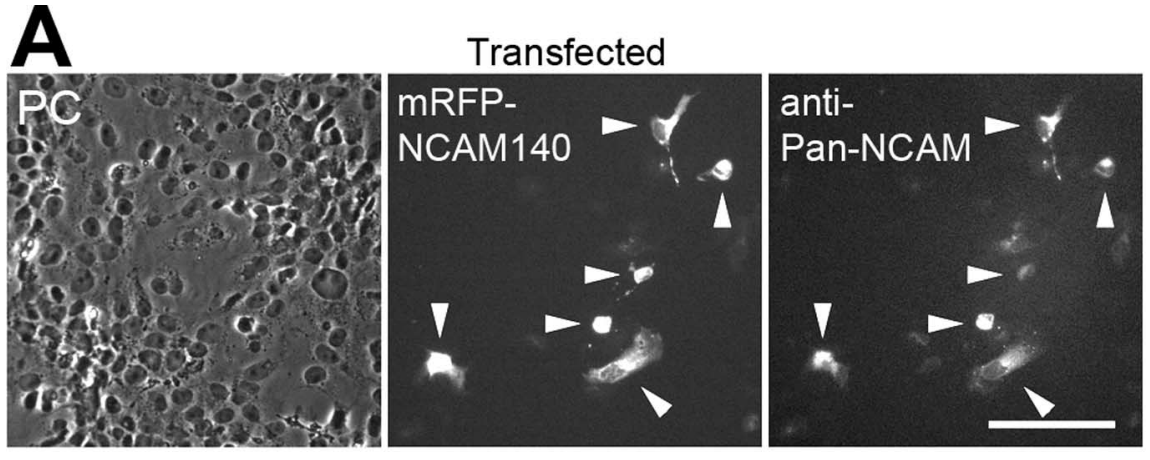

Transfected
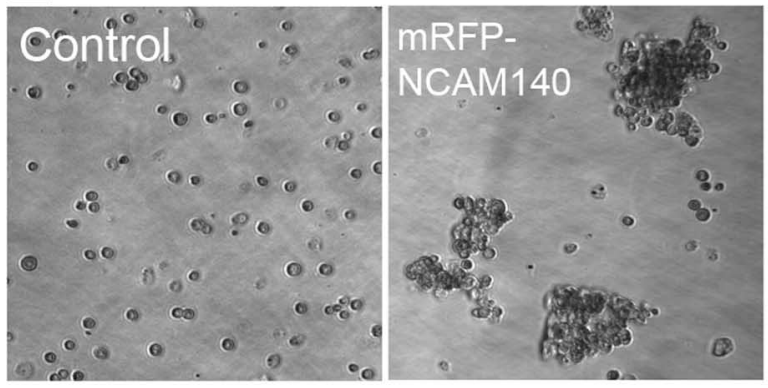

Transfected
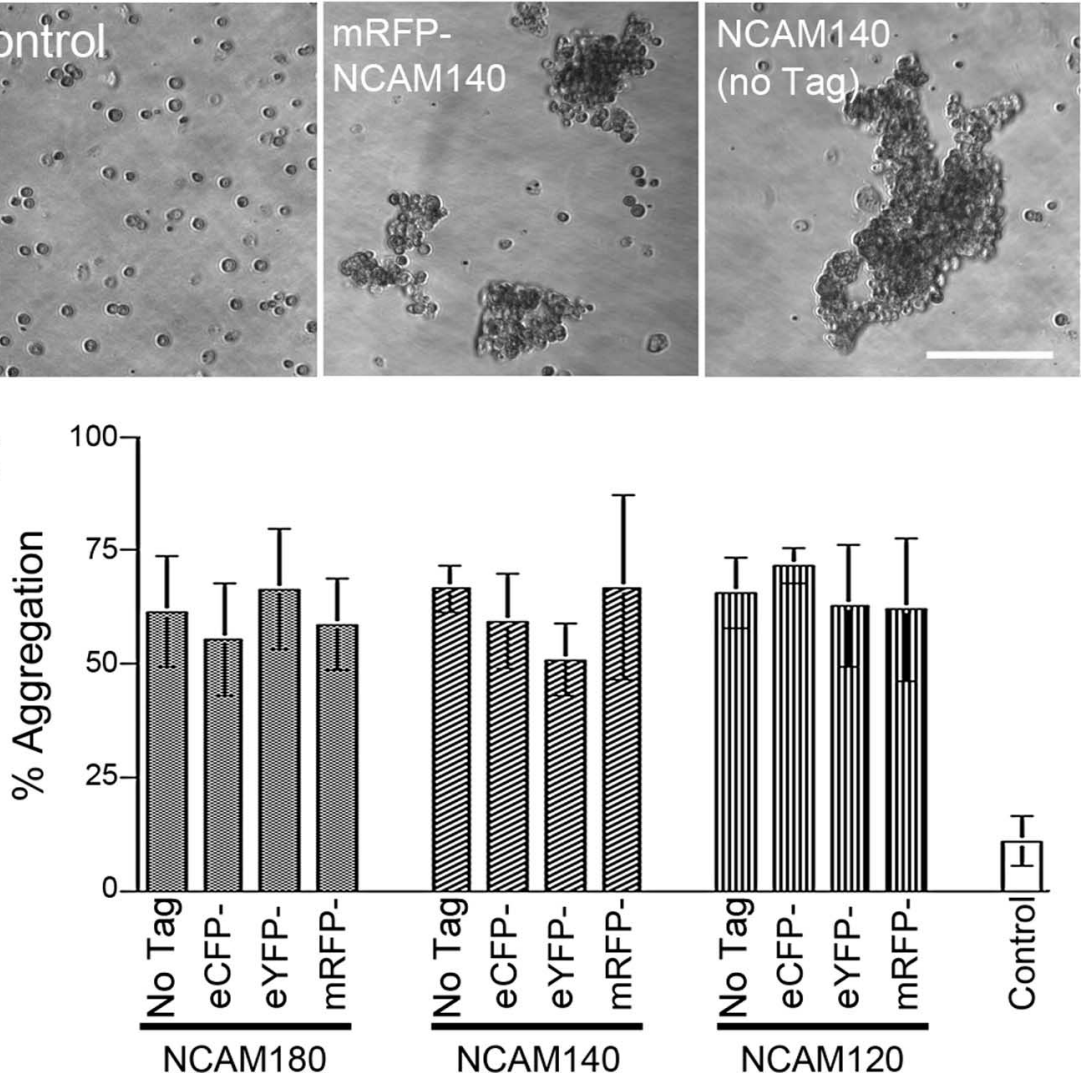

Figure 2. Tagged NCAM isoform constructs are functional and mediate cell adhesion and aggregation in COS-7 cells. $A, \operatorname{COS}-7$ cells (which do not express endogenous NCAM) were transfected with fluorescently tagged NCAMs and immunostained by anti-mouse NCAM13. The fluorescent tag was observed only in transfected cells (arrows, middle), and the same cells were stained by the pan-NCAM antibody (arrows, right). Scale bar, $50 \mu \mathrm{m}$. $\boldsymbol{B}$, Nontransfected COS-7 cells (left) do not aggregate, but those transfected with either an untagged 140 NCAM construct (right) or with the mRFP tagged NCAM 140 (middle) exhibit robust aggregation. Scale bar, $100 \mu \mathrm{m}$. C, The bar graph quantifying the degree of aggregation (percentage of cells in aggregate) shows that all of the tagged constructs were able to mediate aggregation and that the tagged constructs therefore were capable of mediating functional adhesion compared with the nontransfected control cells. were distributed in a pattern similar to the endogenous isoforms, we made use of the $4 \mathrm{D}$ antibody, which recognizes the 180 isoform of the chick but not the mouse (Watanabe et al., 1986). As shown in Figure 4, $A$ and $B$, the transfected mRFP-NCAM 180 was targeted very similarly to the endogenous 180 isoform. This is especially clear when comparing higher magnification views of the axon $(A 1, B 1)$ and growth cones $(A 2, B 2)$ where the pixel intensity is color coded. These results suggest that the addition of the fluorescent tag did not impair the appropriate targeting of 

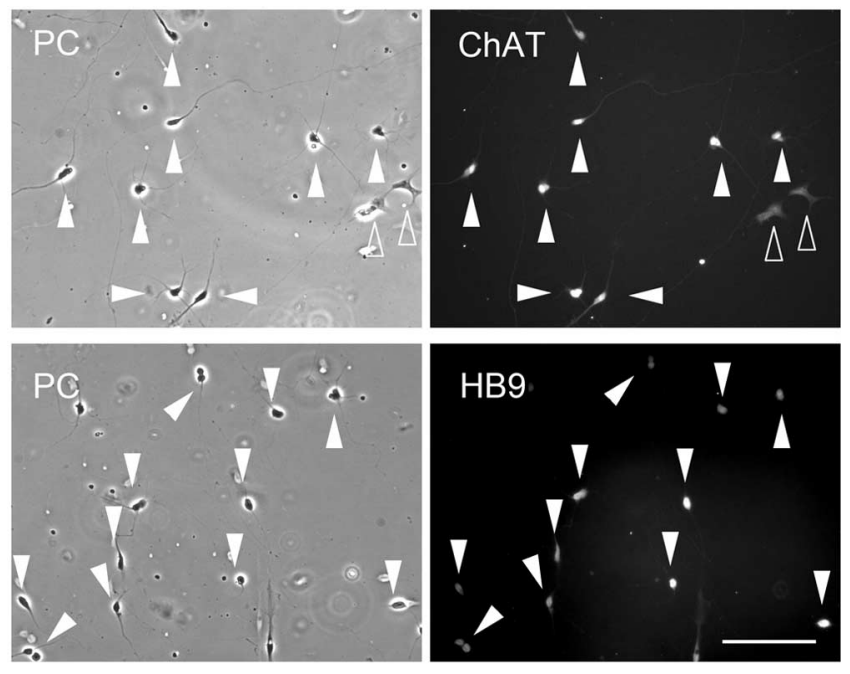

Figure 3. Most cells dissociated from St. 25 chick lumbar cords are positive for the motoneuron markers ChAT and HB9. St. 25 chick ventrolateral lumbar cords were dissected, dissociated, and, after $3 \mathrm{~d}$ in culture, immunostained for ChAT (top) or HB9 (bottom). Phase contrast images of the same fields are shown at left. All cells with neuronal morphology expressed ChAT or HB9 (white arrowheads). Occasional cells that did not express these markers (black arrowheads in (hAT immunostained culture) had non-neuronal morphologies. Scale bar, $100 \mu \mathrm{m}$.

this isoform within the motoneuron. It was not possible to confirm that the exogenously expressed 140 isoform was also targeted similarly to the endogenous 140 isoform, because there is no antibody that selectively recognizes this isoform. When a truncated mouse 180 isoform that lacked the KENESKA domain was expressed, it also was targeted very similarly to the endogenous 180 chick NCAM (Fig. 4C,D). This observation indicates that this domain is not essential for synaptic targeting of the 180 isoform, at least not in cells that express all three isoforms of NCAM. Whether the KENESKA truncated 180 isoform would be similarly targeted in motoneurons that lack all isoforms of NCAM remains to be determined. All of the observations and data presented in this report were made on cells that expressed only moderate levels of exogenous NCAM isoforms, similar to endogenous NCAM levels, to avoid artifacts created by high overexpression levels that might alter targeting and create abnormal associations with other proteins.

Distribution of the different NCAM isoforms in motoneurons and myotubes before synapse formation

All three major NCAM isoforms are expressed in chick sciatic nerves at the time of in vivo neuromuscular synapse formation (Tang et al., 1992). However, because antibodies do not exist that can distinguish between all three of the major NCAM isoforms, it has not been previously possible to determine the extent to which they are differentially distributed during motoneuron outgrowth and synapse formation. After being electroporated with the constructs in isolated spinal cord preparations, St. 25, chick lumbar motoneurons were dissociated and grown alone on collagen for $3 \mathrm{~d}$. This stage was chosen because motoneurons are still growing into the limb and have not yet contacted muscle targets and thus should be naive with respect to signals derived from myotube contact. The GPI-linked $120 \mathrm{kDa}$ isoform, when coexpressed with either the 140 or 180 isoform, was observed to have a diffuse localization in the cell body, axon and growth cone (Fig. 5A, left and middle) When expressed alone the 120 isoform also exhibited a diffuse localization (Fig. 5A, right). In contrast both the 140 $\mathrm{kDa}$ and $180 \mathrm{kDa}$ isoforms exhibited a more punctate staining pattern with discrete spots of bright staining along the axon and in the growth cone, in addition to lower intensity staining over most of the axon and growth cone.

The extent to which the 140 and 180 isoforms were colocalized in the same puncta in motoneurons was determined by simultaneously transfecting both isoforms tagged with different fluorophores. Most of the puncta (92\%) in such dually transfected motoneurons cultured alone contained both isoforms (Fig. $5 B$, asterisks), although a small number contained only the 180 or 140 isoform (Fig. 5B, arrowhead and bar graph). Some of these puncta might represent transport packets of vesicular material containing many molecules involved in presynaptic transmitter release, which have been described in cultured hippocampal neurons (Zhai et al., 2001). Alternatively or additionally (Sabo and McAllister, 2003; Sabo et al., 2006), they might represent sites of functional transmitter release and synaptic vesicle cycling along the axon and growth cone (see below). In either case the exogenously introduced tagged molecules appear to be effectively transported into the axon and growth cone.

Myoblasts derived from St. 37 chick embryos were electroporated with tagged mouse 120,140 or 180 isoform constructs and cultured alone on collagen. When observed at $7 \mathrm{~d}$ in vitro (Fig. $5 C$ ), the 120 isoform was diffusely located throughout the cell and did not accumulate at sites of myotube-myotube contact (arrowheads). The 140 isoform, although also expressed in a diffuse manner throughout the myotube, also exhibited enhanced accumulation at sites of contact between myotubes (arrowheads). The exogenously expressed 180 isoform exhibited a more punctate staining pattern, and in contrast to the 140 isoform did not accumulate at myotube-myotube contact sites (arrowhead). Although levels of the 180 isoform protein are below detection in mature skeletal muscle, our laboratory has previously shown that chick myotubes in culture synthesize all three isoforms, but that the 180 isoform is rapidly degraded, at least when myotubes are cultured alone (Rafuse and Landmesser, 1996). We confirmed here that developing myotubes expressed endogenous 180 NCAM by staining the culture with the 180 isoform selective mAb 4D (data not shown).

\section{Characterization of synaptic vesicle cycling in axons and growth cones before synapse formation}

To determine whether the puncta containing the 180 and 140 isoforms were sites of functional vesicle cycling, loading and unloading of the dye FM1-43 (Betz et al., 1996) in response to a 2 min high $\mathrm{K}^{+}$stimulus was performed in motoneurons that had been previously transfected with exogenous mouse 180 or 140 NCAM isoforms. Many of the 180 puncta were sites of stimulus dependent FM1-43 uptake and release (Fig. 6A, top, arrowheads) although some FM1-43 uptake sites were not associated with puncta expressing high levels of the 180 isoform (Fig. 6A, top). Many 180 puncta in both the axon and growth cone also expressed the synaptic proteins syntaxin and SNAP25 (Fig. 6A, middle and bottom). Quantification revealed that at least $50 \%$ of the 180 or the 140 puncta were sites of strong FM1-43 uptake $(59.6 \pm 10.1 \%$ for 180 puncta; $51.0 \pm 7.2 \%$ for 140 puncta). Similarly, close to $40 \%$ of FM1-43 uptake sites had strong staining for the $180(36.7 \pm 13.9 \%)$ or 140 isoform $(37.3 \pm 16.2 \%)$ of NCAM. Because NCAM containing puncta or FM1-43 uptake sites were only counted if there levels were at least $2 \times$ that of background staining along the axon, this measurement underestimates the degree of colocalization of NCAM puncta and FM1-43 uptake sites.

The form of transmitter release and vesicle cycling that occurs 
in cultured Xenopus spinal neurons along the axon and growth cone (Zakharenko et al., 1999) is sensitive to Brefeldin A (BFA). BFA interferes with budding of vesicles from endosomes in an ARF1 and AP3 adaptor protein dependent manner (Faundez et al., 1998). However BFA does not affect FM1-43 loading at the mature mouse NMJ (Polo-Parada et al., 2001) in which vesicle endocytosis in response to moderate stimulation is mediated by a clathrin/ AP2 pathway. In contrast in NCAM null NMJs, a BFA sensitive form of vesicle cycling was found to be maintained at adult NMJs along the preterminal axon and also accounted for 75\% of FM1-43 dye uptake at the synapse (Polo-Parada et al., 2001). This form of vesicle cycling was postulated to represent the retention of the immature form of vesicle cycling when NCAM was absent presynaptically and postsynaptically. However the characteristics of synaptic vesicle cycling in immature chick or mouse motoneurons has not been previously reported.

To characterize the form of endocytosis along the axon before myotube contact, chick motoneurons cultured alone for $7 \mathrm{~d}$ were exposed to a $2 \mathrm{~min}$ stimulus of high $\mathrm{K}^{+}$, which induced $\sim 2.6$-fold more FM1-43 dye uptake than that occurring spontaneously in the absence of high $\mathrm{K}^{+}$. This was used as the control value (Fig. $6 \mathrm{~B}$, high $\mathrm{K}^{+}$control vs normal Tyrode's solution). Application of BFA during loading completely blocked the uptake of dye in response to high $\mathrm{K}^{+}$, indicating that in neurons that have not made contact, all stimulation induced dye uptake is via the immature, BFA sensitive form of endocytosis. In adult NMJs, P/Q type $\mathrm{Ca}^{2+}$ channels account for virtually all of the $\mathrm{Ca}^{2+}$ influx involved in transmitter release (Hong and Chang, 1995; Polo-Parada et al., 2001). Thus both transmission and FM1-43 dye uptake are blocked by the P/Q channel antagonist $\omega$-agatoxin TK. In contrast FM1-43 dye uptake at axonal puncta in motoneurons cultured alone was insensitive to $\omega$-agatoxin TK (Fig. 6 B). Nifedipine, an L-type channel antagonist blocked most of the FM1-43 dye uptake, with a smaller amount being blocked by the N-type channel antagonist $\omega$-conotoxin GVIA. Virtually all dye uptake, including that occurring spontaneously in the absence of stimulation, was blocked by the general $\mathrm{Ca}^{2+}$ channel antagonist cobalt chloride (Sundgren-Andersson and Johansson, 1998), indicating that all uptake was $\mathrm{Ca}^{2+}$ dependent.

\section{After myotube contact, the 140 and 180 NCAM isoforms are selectively targeted to the presynaptic terminal}

To assess any changes in NCAM isoform distribution after myotube contact, St. 25 ventral neural tube explants from spinal cords that that been electroporated with the different tagged isoforms of NCAM were either cultured alone on collagen or were plated onto cultures of chick myotubes grown on collagen, both for up to $7 \mathrm{~d}$. In both cases, many axons extended long distances from the explant and those chosen for quantification were single axons that could be followed for relatively long comparable distances. In $7 \mathrm{~d}$ motoneurons grown alone, numerous puncta of 180 NCAM were distributed throughout the axon and growth cone
(Fig. 7A, top). These could be quantified by the expression of pixel intensity along the length of the axon (trace below axon shows many peaks of increased pixel intensity indicating puncta). In contrast, after contact with myotubes most of the 180 isoform became concentrated at the presynaptic terminal (Fig. 7A, bottom, white arrowhead; myotube outlined by dashed lines) and was downregulated from the axon (black arrowheads; see also pixel intensity trace below).

We quantified this shift in isoform distribution in two ways. First the spatial distribution of 180 puncta along the axon from the tip proximally was measured. As shown in Figure $7 B$, in $3 \mathrm{~d}$ motoneurons cultured alone, puncta were distributed relatively uniformly from the growth cone to the proximal axon. By $7 \mathrm{~d}$, in motoneurons grown alone there was a slight tendency to have puncta redistribute toward the distal tip. However in $7 \mathrm{~d} \mathrm{mo-}$ toneurons which had contacted myotubes, most proximal puncta along the axon had disappeared and NCAM 180 was selectively expressed at the presynaptic terminal. This shift was also quantified by measuring the mean pixel intensity of the presynaptic terminal compared with axon proximal to the terminal. These measurements demonstrated that both the 180 and 140 isoforms had been selectively accumulated at the presynaptic terminal (Fig. 7C) and strongly downregulated along the length of the axon. In contrast the 120 isoform was relatively uniformly distributed between the presynaptic terminal and the axon. To assess whether the KENESKA domain played a role in the targeting of the 180 isoform to the presynaptic terminal, the distribution of the KENESKA truncated form of the 180 isoform was assessed. This did not differ from the distribution of the fulllength180 isoform (Fig. 7C). Thus the KENESKA domain is not required for the selective accumulation of the 180 isoform at presynaptic terminals after myotube contact, at least not in chick 

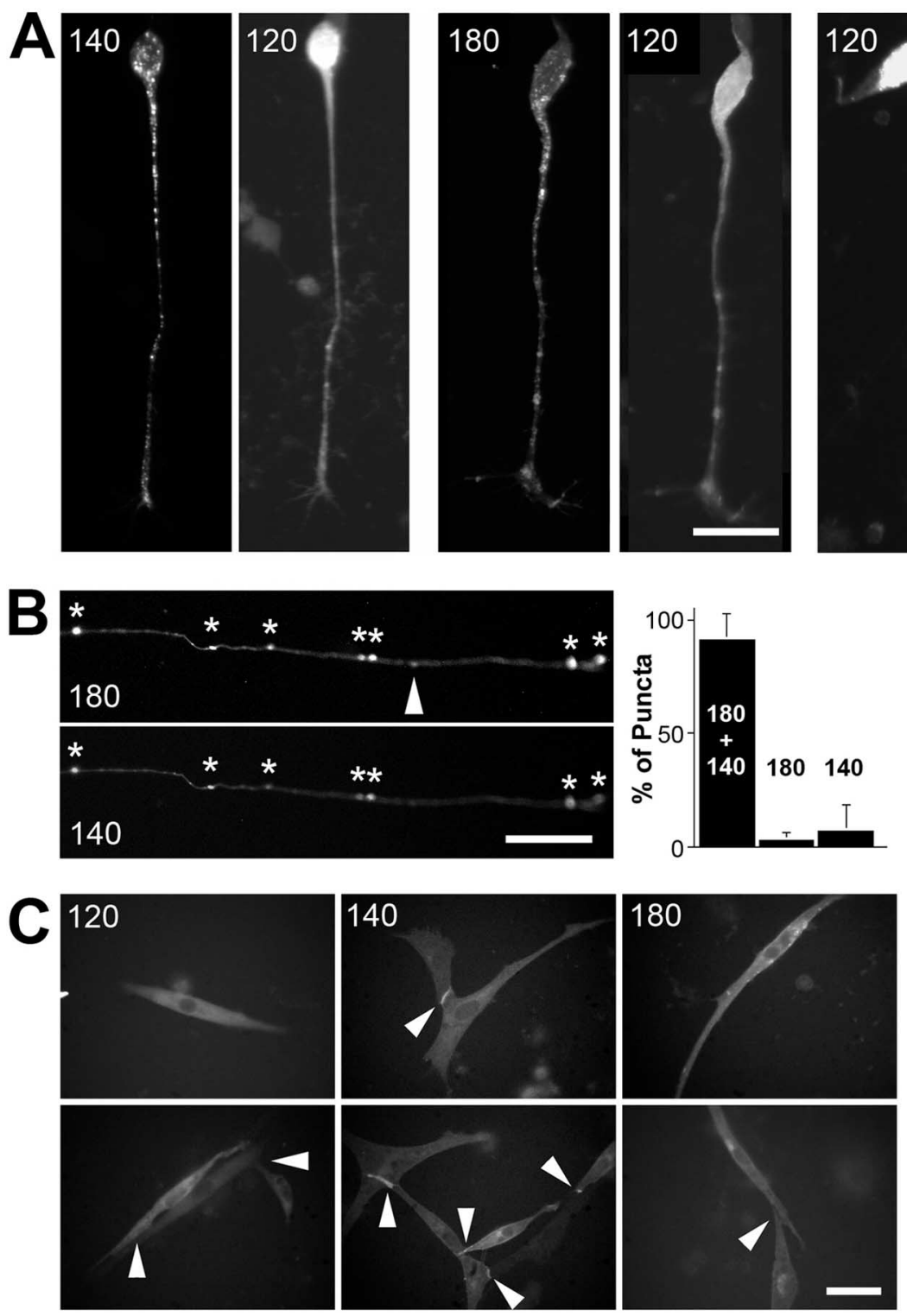

Figure 5. The distribution of 120,140 , and 180 NCAM isoforms in motoneurons and myotubes before synapse formation. $A$, Left and Middle, St. 25 dissociated chick motoneurons that had been dually transfected with either 120 and 140 or 120 and 180 isoforms and grown alone on collagen for $3 \mathrm{~d}$. The 120 isoform was diffusely expressed whereas the 140 and 180 isoforms were expressed in distinct puncta in the cell body and axon. The 120 isoform also exhibited a diffuse localization when transfected alone (right). Scale bar, $10 \mu \mathrm{m} . \boldsymbol{B}$, When the 180 and 140 isoforms were coexpressed, most of the puncta along the axon contained both the 180 and 140 isoforms (asterisks and bar graph at right), whereas a small number expressed only one or the other isoform (arrowhead). Scale bar, $5 \mu \mathrm{m}$. C, Examples of myotubes at $3 \mathrm{~d}$ in culture that had been transfected with the 120 (left), 140 (middle), or 180 isoform (right). The 140 isoform selectively accumulated at contact sites between myotubes (arrowheads), whereas the 120 and 180 did not. Scale bar, $5 \mu \mathrm{m}$.

motoneurons that contain all three full-length isoforms of NCAM.

Functional vesicle cycling is downregulated from the axon after myotube contact

In contrast to axons which had not made contacts with myotubes (Fig. 8A, left) and which retained sites of stimulus dependent FM1-43 uptake along the axon, motor axons that had made a clear contact with a myotube, as visualized by the strong expression of the 180 isoform in the presynaptic terminal (Fig. $8 A$, top right, white arrowhead) only took up FM1-43 in response to high $\mathrm{K}^{+}$stimulation at the presynaptic terminal (Fig. $8 \mathrm{~A}$, bottom right, white arrowhead). There were no puncta of either NCAM

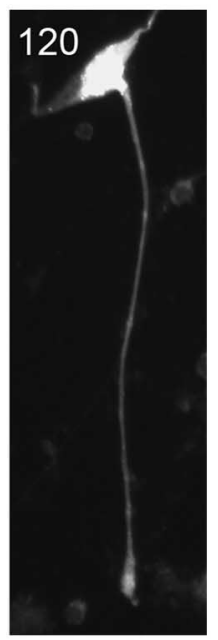

180 or FM1-43 along the length of the axon (black arrowheads). When mean pixel intensity of FM1-43 fluorescence of the proximal axon was compared with that at the terminal (Fig. $8 \mathrm{~B}$ ), it was clear that FM1-43 dye uptake was completely downregulated from the axon and compared with the uptake at free axonal tips, was greatly increased at the presynaptic terminal. Such dye uptake in response to a $2 \mathrm{~min}^{+}$stimulus was quantified after quenching with bath application of sulfrhodamine to remove any FM1-43 fluorescence that was on the surface membranes and could thus contribute to artifacts in quantifying dye uptake into cycling vesicles. FM1-43 dye in vesicles within the cell is not affected by this procedure. In addition we always confirmed that the dye that was taken up by a high $\mathrm{K}^{+}$stimulus could be released by a second high $\mathrm{K}^{+}$stimulus (data not shown). Similar to the 140 and 180 NCAM isoforms, SNAP25 and syntaxin, which were also distributed in puncta along the axon before myotube contact (Fig. 6A), were also selectively localized to the synapse after myotube contact (Fig. $8 C$, white arrowheads; myotube outlined by dotted lines). The levels of both SNAP25 and syntaxin were also strongly downregulated from the length of the axon (black arrowheads) compared with the presynaptic terminal.

After myotube contact, synaptic vesicle endocytosis at the nerve terminal becomes BFA insensitive and is mediated by $\mathrm{P} / \mathrm{Q}$ type $\mathrm{Ca}^{2+}$ channels In cultures in which explants had been grown for $7 \mathrm{~d}$ in the presence of myotubes, we located isolated myotubes on which a single axon had made a clear terminal contact visualized both in phase contrast and by the accumulation of the fluorescently tagged 180 isoform of NCAM (Fig. 9A). Such terminals were then loaded with FM1-43 by a 2 min high $\mathrm{K}^{+}$stimulus, and then after washout of the dye, a second high $\mathrm{K}^{+}$stimulus was applied to show that the loaded dye could be released and thus indicated sites of functional synaptic vesicle cycling (Fig. 9B). Subsequently the same terminal was subjected to a second high $\mathrm{K}^{+}$stimulus in the presence of FM1-43 and a drug such as BFA. The top of Figure $9 B$ shows that BFA had no effect on the uptake of FM1-43 and thus that this contact (the same as that shown in A) exhibited the mature form of synaptic vesicle endocytosis; additionally it was demonstrated that the dye taken up under these conditions could be subsequently released by a second high $\mathrm{K}^{+}$stimulus. The bottom panel shows that FM1-43 dye uptake in response to a second high $\mathrm{K}^{+}$stimulus was almost completely blocked by $\omega$-agatoxin TK and thus that the vesicle cycling was dependent on P/Q type channels as in the adult NMJ. The data from a number of contacts is quantified in the bar graph in Figure 

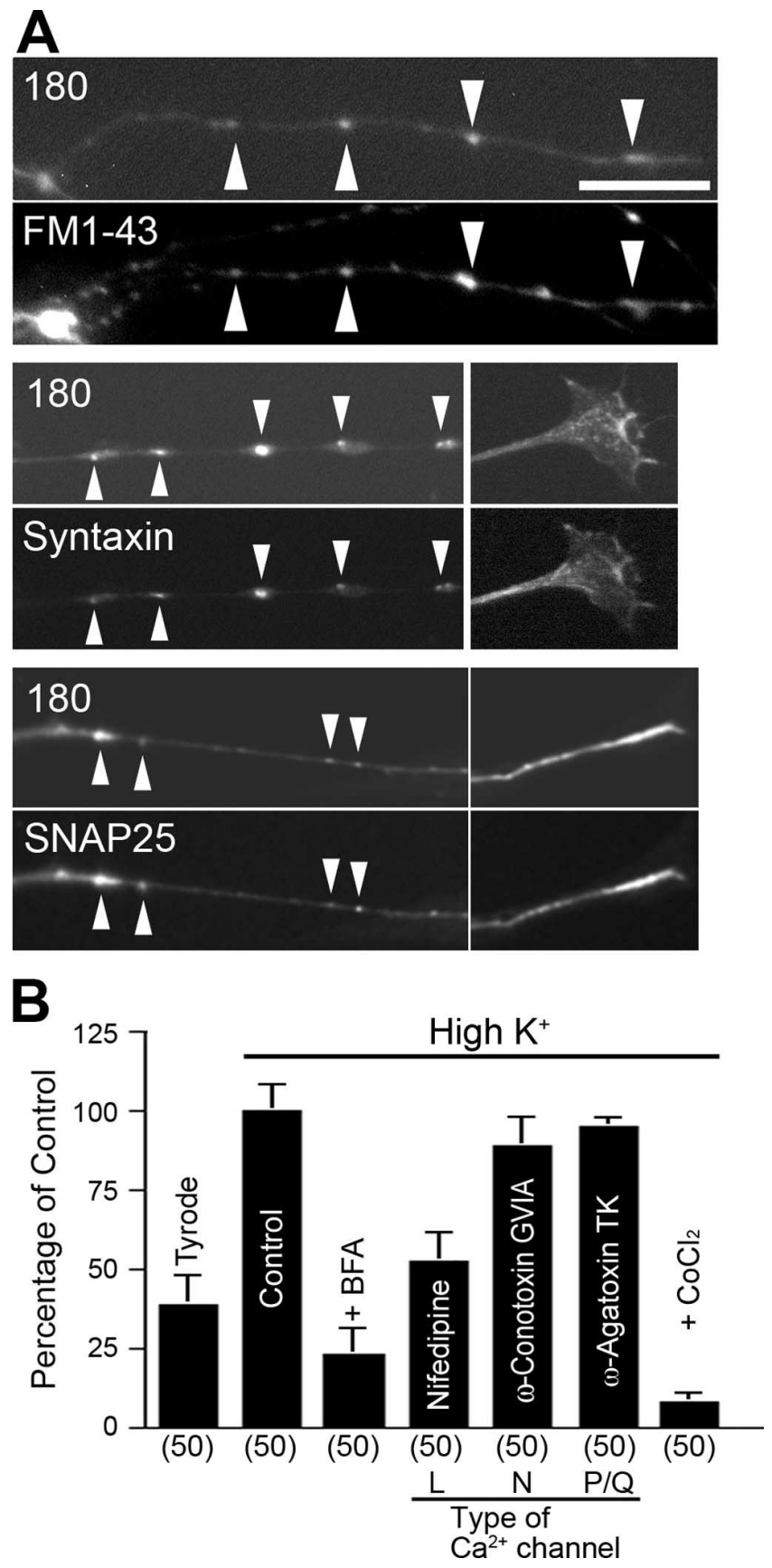

Figure 6. Characterization of the properties of synaptic vesicle cycling and its relationship to puncta containing 180 or 140 NCAM isoforms along axons in motoneurons grown alone. $A$, Top pair, Many sites of FM1-43 uptake in response to high $\mathrm{K}^{+}$stimulation (bottom) occurred at puncta containing the 180 isoform (top, arrowheads). Middle and bottom pairs, Many 180 puncta also expressed the presynaptic proteins syntaxin and SNAP25, respectively. Scale bar, 5 $\mu \mathrm{m} . \boldsymbol{B}$, The properties of FM1-43 uptake in response to a high $\mathrm{K}^{+}$stimulus. When compared with spontaneous uptake in Tyrode's solution without stimulation, high $\mathrm{K}^{+}$elicited a 2.6 -fold increase in uptake that was normalized to $100 \%$. BFA blocked this stimulus-dependent uptake. The $\mathrm{P} / \mathrm{Q}$ type $\mathrm{Ca}^{2+}$ channel blocker $\omega$-agatoxin TK was without effect on the uptake, whereas the L-type $\mathrm{Ca}^{2+}$ channel blocker nifedipine blocked most of the uptake with the N-type channel blocker $\omega$-conotoxin GVIA blocking to a lesser extent. The general $\mathrm{Ca}^{2+}$ channel antagonist cobalt chloride blocked both the spontaneous and stimulated uptake of FM1-43.

9C. In summary FM1-43 uptake at contact sites was affected only slightly by BFA or by the $\mathrm{L}$ or $\mathrm{N}$ type $\mathrm{Ca}^{2+}$ channel antagonists, but was almost completely blocked by the P/Q type channel blocker $\omega$-agatoxin TK. Uptake was also blocked by the general $\mathrm{Ca}^{2+}$ channel blocker cobalt chloride.
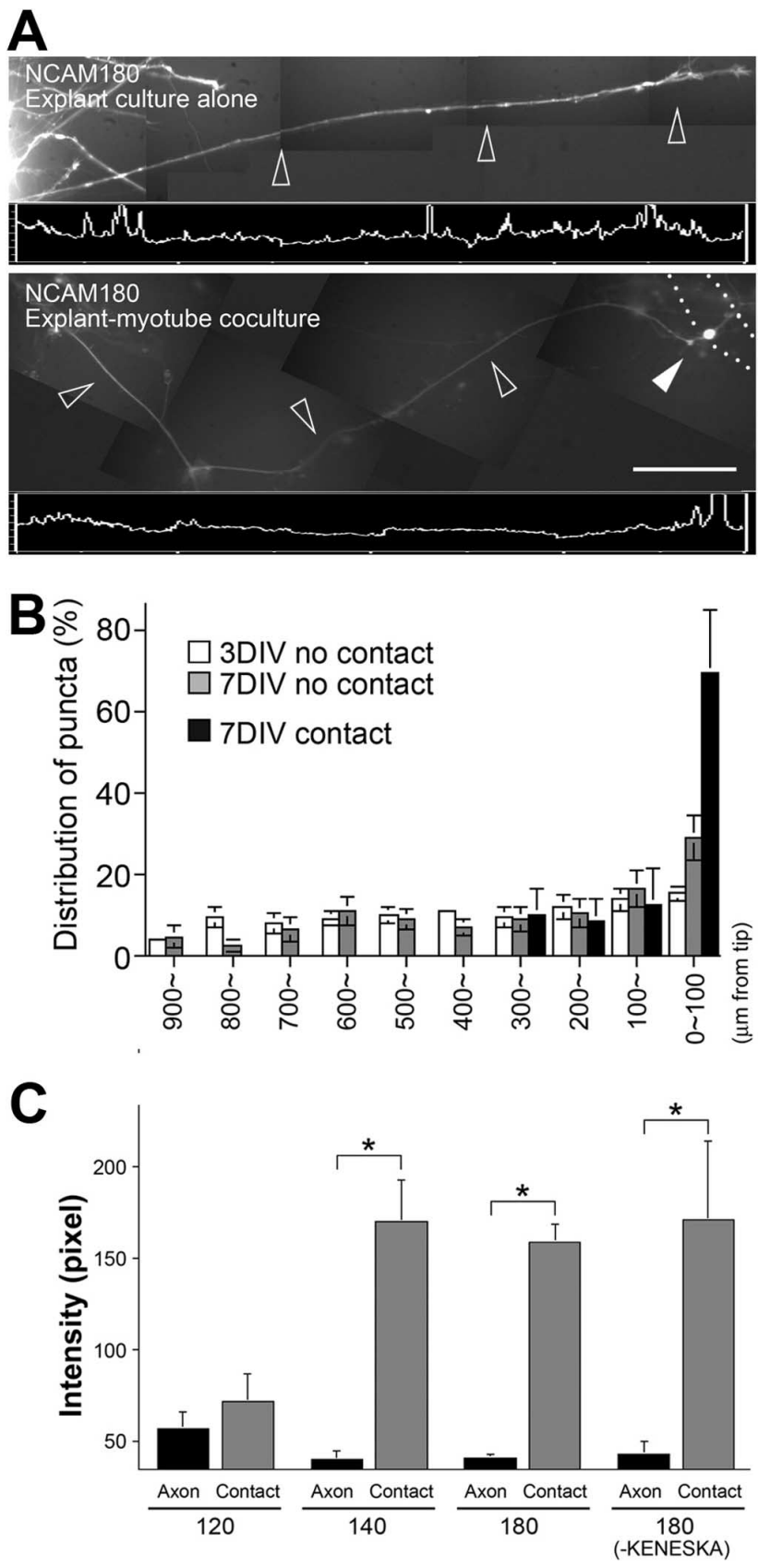

Figure 7. The selective targeting of the 180 and 140 isoforms to the presynaptic terminal after myotube contact. $A$, St. 25 ventral neural tube explants electroporated with the 180 NCAM isoform were grown alone or in an explant-myotube coculture for $7 \mathrm{~d}$. In the explant grown alone (top), puncta of the 180 isoform were distributed along the entire length of the axon (black arrowheads indicate trajectory of axon). The trace below represents pixel intensity along the axon shown above and exhibits many peaks indicating puncta. In an axon that had made contact with a myotube (bottom; myotube outlined with dotted lines, contact site by white arrowhead), puncta had disappeared from the axon (black arrowheads), and all isoform was concentrated at the presynaptic terminal. The trace below quantifying pixel intensity along the axon shows no peaks except at the synapse. Scale bar, $100 \mu \mathrm{m}$. B, A comparison of the distribution of 180 positive puncta along the length of the axon proximally from the distal tip at 3 and $7 \mathrm{~d}$ in cultures of explants grown alone and in explants grown for $7 \mathrm{~d}$ with myotubes. Although there was a slight tendency for puncta in free axons to accumulate more distally between 3 and $7 \mathrm{~d}$, after myotube contact there was a complete loss of puncta long the proximal axon and a strong accumulation at the contact site. C, Quantification of the mean pixel intensity of 180, 140 , and 120 isoform fluorescence at the contact site compared with the proximal axon after $7 \mathrm{~d}$ in culture $\left({ }^{*} p<0.01\right)$. Although the distribution of the 120 isoform was not statistically different between proximal axon or contact site, the 140 and 180 isoforms were downregulated from the proximal axon and strongly accumulated at the contact site. This selective accumulation also occurred in the 180 isoform lacking the KENESKA domain. 

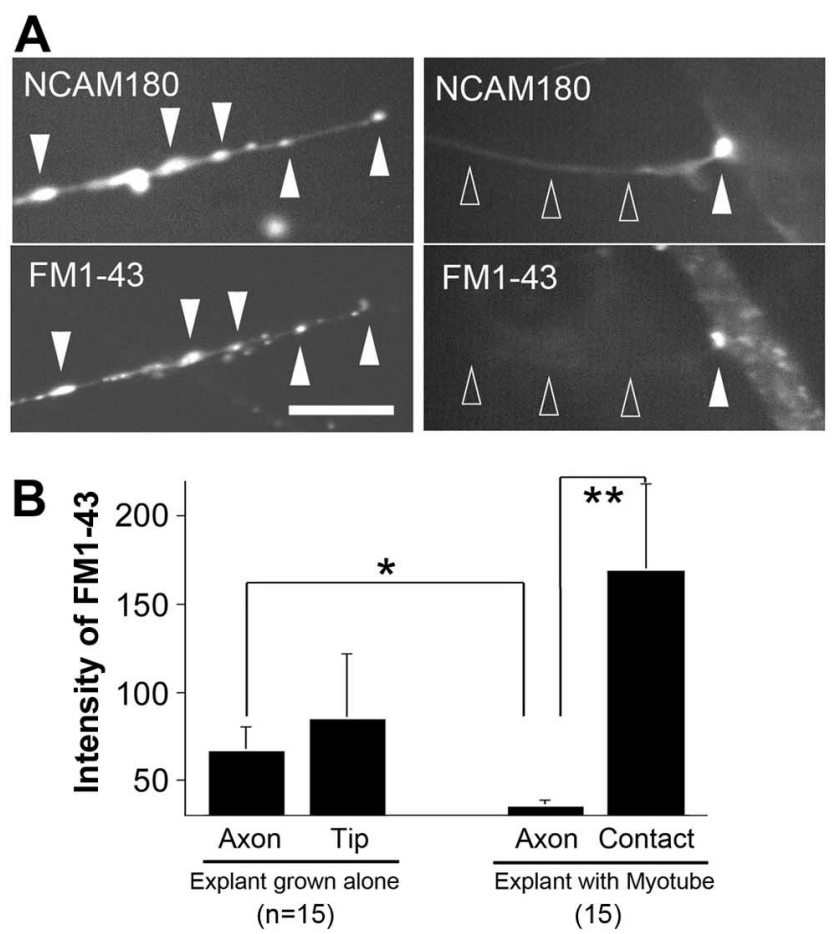

C
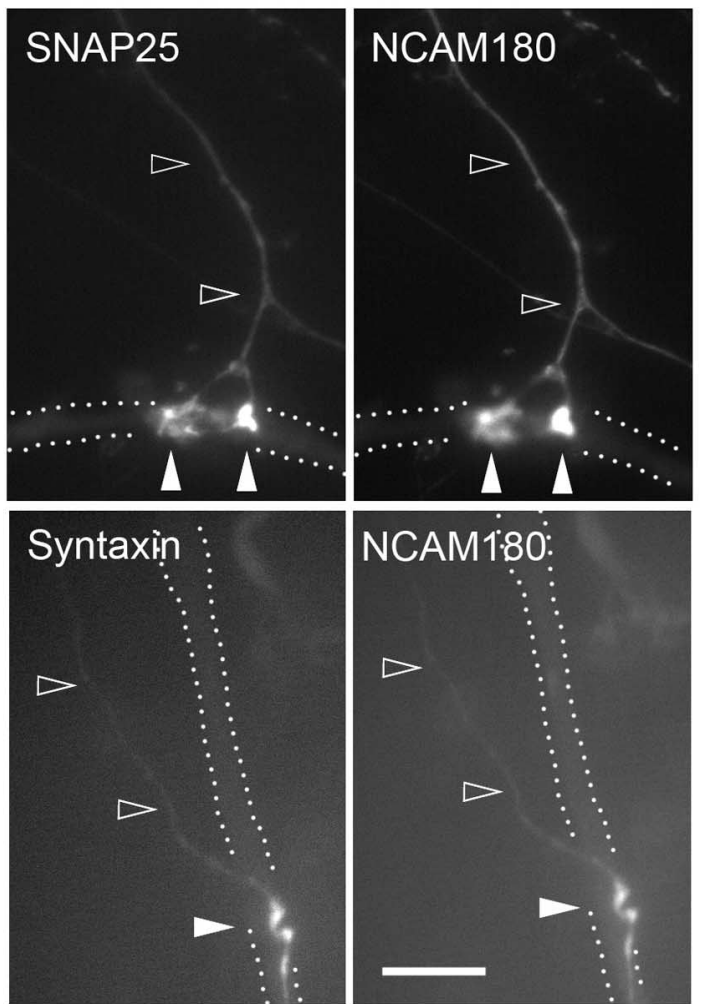

Figure 8. The spatial location of sites of synaptic vesicle cycling defined by stimulusdependent FM1-43 uptake before and after myotube contact. $A$, Examples of FM1-43 dye uptake after a high $\mathrm{K}^{+}$stimulus in a free axon (bottom, left) versus one that had made contact with a myotube (bottom right). The top row shows the expression of exogenous 180 NCAM isoform expression in the same axons. White arrowheads indicate some sites of FM1-43 dye uptake (bottom left) or 180 isoform expression (top left) along the axon that had not made contact. On the right, black arrowheads indicate downregulation of both 180 isoform expression (top) and FM1-43 uptake (bottom) from along the axon that had made myotube contact, whereas FM1-43 uptake remains strongly at contact site (white arrowhead). Scale bar, $10 \mu \mathrm{m}$. $B$, Quantification of FM1-43 dye uptake expressed as the mean pixel intensity of either the free axon tip or contact site compared with the proximal axon $\left({ }^{*} p<0.05,{ }^{* *} p<0.01\right)$. C, Examples
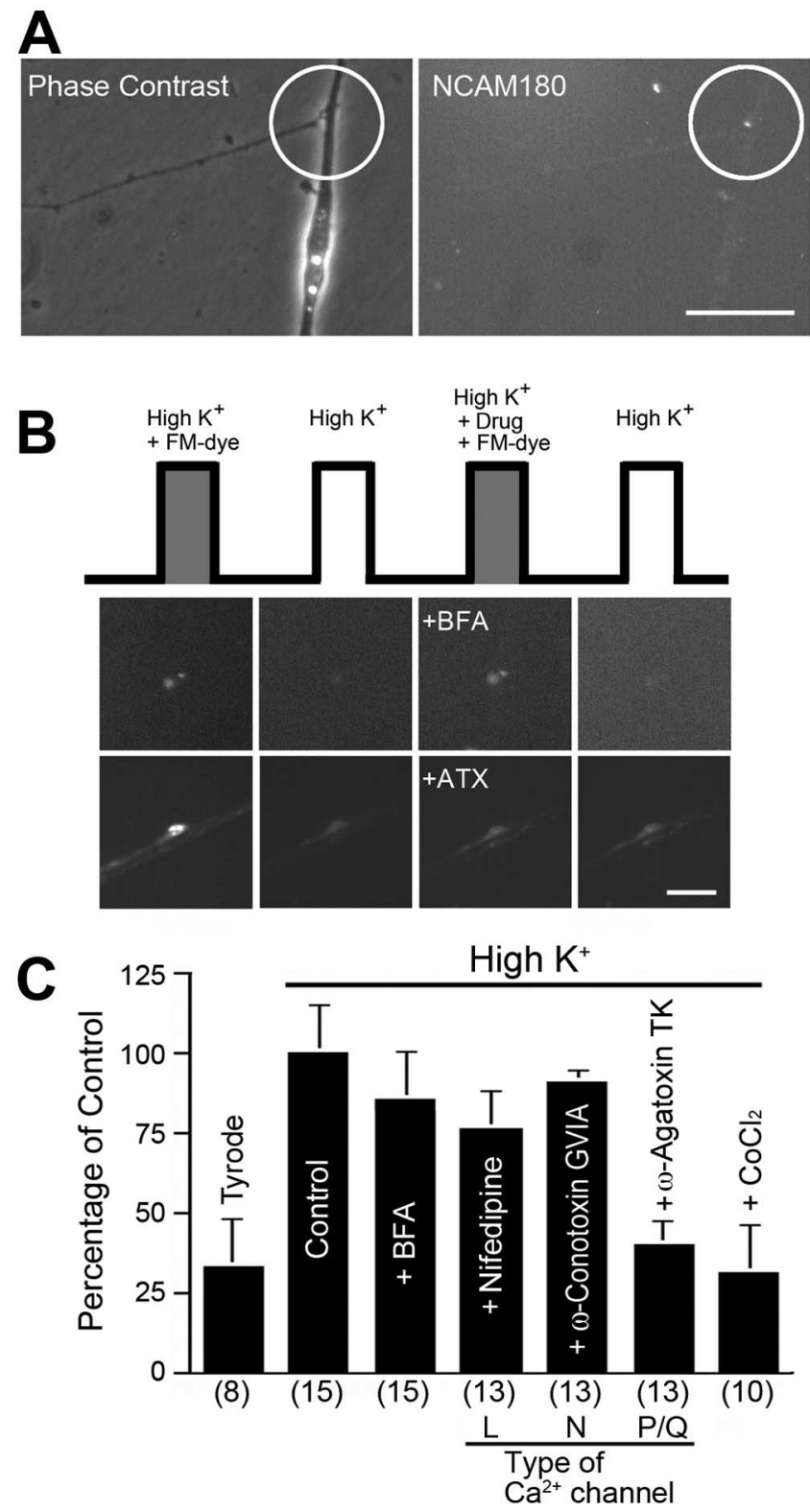

Figure 9. Characteristics of FM1-43 dye uptake at synaptic contacts between motor axons and myotubes. $A$, An example of a single axon making a clear myotube contact as visualized in phase contrast (left) and by the accumulation of the 180 isoform at the contact site (right). $\boldsymbol{B}$, Examples of the FM1-43 dye uptake paradigm. $\mathrm{A} 2$ min high $\mathrm{K}^{+}$stimulus resulted in uptake of dye that could be released by a second high $\mathrm{K}^{+}$stimulus after washout of dye. This served as the control loading. The same contact was then subjected to a third high $\mathrm{K}^{+}$stimulus in the presence of FM1-43 dye and BFA (top). A subsequent high $\mathrm{K}^{+}$stimulus was able to release the dye taken up in the presence of $B F A$, indicating that BFA did not prevent dye uptake. Exposure of another contact to $\omega$-agatoxin TK (bottom ATX) showed that $\omega$-agatoxin TK blocked uptake. $C$, A bar graph comparing the uptake of FM1-43 either taken up spontaneously (Tyrode) or after a high $\mathrm{K}^{+}$stimulation in the absence of drug or in the presence of $\mathrm{BFA}$, or L, $\mathrm{P} / \mathrm{Q}$, or N type $\mathrm{Ca}^{2+}$ channel antagonists. The uptake in the presence of drugs is expressed as a percentage of the control high $\mathrm{K}^{+}$stimulated uptake.

$\leftarrow$

showing that SNAP 25 (top) and syntaxin (bottom) are also selectively targeted to the presynaptic terminal (white arrowheads) after myotube contact. The myotubes are outlined with dotted lines. The black arrowheads point out the more proximal axon in which both SNAP25 and syntaxin have been downregulated. The 180 isoform has been similarly downregulated from the axon (right top and bottom). 
Because it usually took $\sim 2$ or $3 \mathrm{~d}$ for axons to extend from the explants far enough to contact the myotubes we used in this analysis, the results show that as early as $5 \mathrm{~d}$ after myotube contact the transmitter release and vesicle cycling has already switched from the immature to the mature form. Time lapse imaging of contact formation will be required to determine how rapid the switch actually occurs. It should be pointed out that, although much of the data that is presented in Figures 8 and 9 was taken from motoneurons that had been transfected with the 180 isoform of NCAM, similar alterations in the sensitivity of FM1-43 dye uptake to BFA and $\mathrm{Ca}^{2+}$ channel antagonists occurred in nearby nontransfected axons. In addition, although this was not routinely done, in a number of cases the explants were stimulated with a suction electrode. These elicited contractions in some myotubes indicating that the contacts made were sites of functional transmission.

\section{Targeting of presynaptic 180 and 140 NCAM isoforms on motoneuron contact with $\mathrm{NCAM}^{+/+}$or $\mathrm{NCAM}^{-/-}$mouse myotubes}

Studies from the $\mathrm{NCAM}^{-/-}$and NCAM $180^{-/-}$mice (PoloParada et al., 2001, 2004) showed that both the 180 and 140 NCAM isoforms were required for distinct aspects of presynaptic maturation at mouse NMJs. However it was not clear whether the different NCAM isoforms were required presynaptically or postsynaptically. To test for the requirement of postsynaptic NCAM in the selective presynaptic targeting of the 180 and 140 isoforms that we observed in the present study, chick motoneurons expressing the tagged 180 or 140 mouse isoforms were cultured with either wild type mouse myotubes or with mouse myotubes that lacked all isoforms of NCAM.

When motoneurons contacted wild type myotubes we observed that both the 180 and 140 isoforms exhibited selective targeting to the presynaptic terminal (Fig. $10 \mathrm{~A}$, top and bottom, white arrowheads; myotubes outlined by dotted lines), and that their expression was downregulated from along the axon (black arrowheads). Interestingly the 180 isoform was also selectively targeted to the presynaptic terminal after motoneurons contacted NCAM ${ }^{-1-}$ myotubes (Fig. $10 \mathrm{~B}$, top). This finding shows that the presynaptic 180 isoform does not have to interact transynaptically with postsynaptic NCAM for selective targeting to occur. The presynaptic 180 isoform may be interacting heterophilically with other postsynaptic molecules such as CD 24 (Jevsek et al., 2006). CD 24 is preferentially synthesized by subsynaptic myonuclei and CD 24 deficient mice exhibit similar transmission deficits as the 180 deficient mouse. Alternatively the 180 isoform might interact with synaptic basal lamina components such as agrin (Storms et al., 1996; Bixby et al., 2002). Finally, synaptic targeting could be mediated by cis-interactions with other presynaptic molecules.

In striking contrast to the findings with the 180 isoform, we found that the 140 isoform was not selectively targeted to the synapse (Fig. $10 \mathrm{~B}$, bottom, white arrowhead) after motoneuron contact with NCAM deficient myotubes, but remained localized in puncta along the length of the axon (black arrowheads). Thus the selective presynaptic localization of the 140 isoform requires postsynaptic NCAM. Together, these observations reveal interesting differences in the mechanisms by which the 140 and 180 isoforms are targeted to the presynaptic terminal as well as differences in the requirement for postsynaptic NCAM in this process.
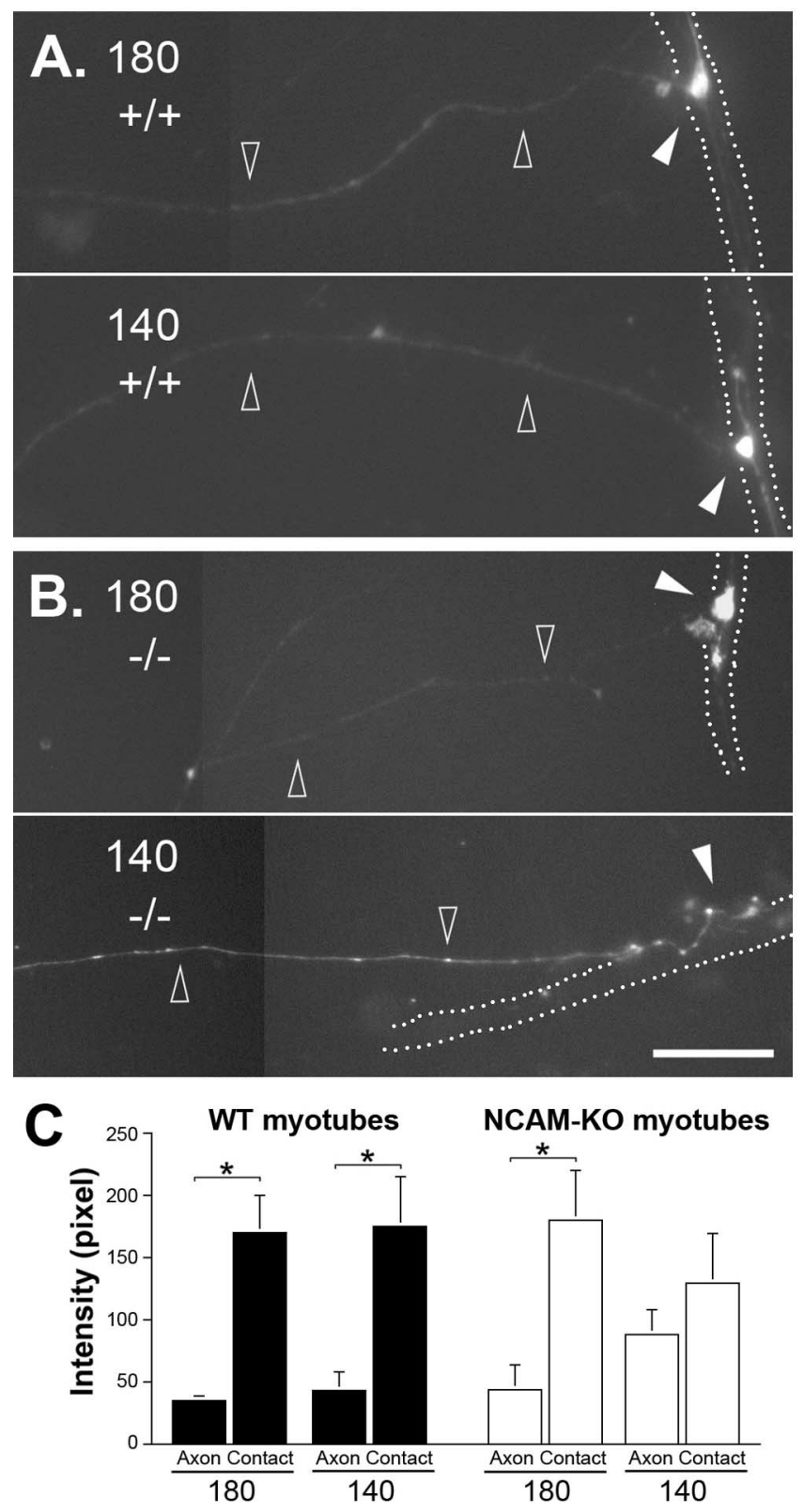

Figure 10. Targeting of exogenously expressed presynaptic 180 and 140 NCAM isoforms after motoneuron contact with wild-type or NCAM-deficient mouse myotubes. $\boldsymbol{A}$, The localization of the 180 (top) and 140 (bottom) tagged isoforms after chick motoneurons contact wildtype mouse myotubes in 7 DIV cultures. Clear synaptic localization is obvious at myotube contact sites (white arrowheads) for both the 180 and 140 isoforms (the myotubes are outlined by dotted line). $\boldsymbol{B}$, In contrast, when contacting NCAM ${ }^{-1-}$ myotubes, the 180 isoform (top) but not the 140 isoform (bottom) was synaptically targeted. White arrowheads denote myotube contact sites and black arrowheads the more proximal axon showing the downregulation of the 180 isoform from along axon (top), whereas many 140 puncta remain (bottom). Dashed lines outline the borders of contacted myotubes. C, Quantification of NCAM isoform levels in the presynaptic terminal and in the proximal axon. Data are expressed as mean \pm SEM pixel intensity. For the 180 isoform, there was a statistically significant accumulation at the synapse and a downregulation from the proximal axon after contact with both wild-type (filled bars; ${ }^{*} p<0.01$ ) and NCAM-deficient (open bars; ${ }^{*} p<0.01$ ) myotubes. In contrast, the 140 isoform only exhibited selective synaptic localization when contact was made with NCAM containing myotubes (filled bars; ${ }^{*} p<0.01$ ).

\section{Discussion}

A major finding of this study is that in developing chick motoneurons in response to myotube contact, an immature form of synaptic vesicle cycling along the axon, that is BFA sensitive and 
mediated by L-type and, to a lesser extent, $\mathrm{N}$-type $\mathrm{Ca}^{2+}$ channels, is downregulated and replaced by a BFA insensitive, $\mathrm{P} / \mathrm{Q}$ type $\mathrm{Ca}^{2+}$ channel mediated mature form of cycling selectively targeted to the presynaptic terminal. The failure of this step of synaptic maturation to occur in the NCAM deficient, but not the NCAM 180 isoform deficient, mouse indicates that the 140 or 120 isoform is sufficient for this important developmental switch to take place.

Early studies indicated that ACh could be released from growth cones and axons in cultured Xenopus motoneurons, and thus that these aspects of presynaptic differentiation occurred autonomously and did not require retrograde signals from the myotubes (Sun and Poo, 1987). It was subsequently shown (Zakharenko et al., 1999) that this immature form of synaptic vesicle cycling was molecularly distinct in that it was sensitive to BFA. However in the latter study the $\mathrm{Ca}^{2+}$ channel mediating this form of vesicle cycling was $\mathrm{N}$-type as in mature Xenopus NMJs ( $\mathrm{Za}$ kharenko et al., 1999). In contrast, other studies of developing Xenopus junctions in culture have found that L-type $\mathrm{Ca}^{2+}$ channels (Sand et al., 2001), as found in the present study to mediate immature cycling along chick axons, makes an important contribution to transmitter release in these apparently immature junctions. This channel may also play a modulatory role at immature synapses (Sugiura and Ko, 1997). Thus, although different aspects of transmitter release/synaptic vesicle cycling have been characterized at different developmental stages in Xenopus or mouse NMJs, the present study is the first to demonstrate in a single species (chick) a rapid switch, in BFA sensitivity and the type of $\mathrm{Ca}^{2+}$ channel mediating transmitter release, in response to myotube contact. Additionally, although Chow and Poo (1985) described the downregulation of transmitter release in cultured Xenopus axons as a response to myotube contact, a subsequent study concluded that this occurred autonomously as a result of maturation (Antonov et al., 1999). The present study supports the previous conclusion (Chow and Poo, 1985) (see also DiGregorio et al., 2001) because vesicle cycling was completely downregulated on 7DIV axons that had made contact with myotubes but not on those that had not. Vesicle cycling along axons before synapse formation has also been described in hippocampal neurons (Matteoli et al., 1992) and such sites have recently shown to be highly mobile (Krueger et al., 2003). The cycling along axons in hippocampal neurons also appears to be molecularly distinct as it was not blocked by tetanus toxin, which blocked vesicle cycling at synaptic sites (Verderio et al., 1999).

The extent to which such early forms of synaptic vesicle exocytosis and endocytosis from the axon and growth cone of extending axons play a role in neuromuscular development is not clear. However in vivo, chick and mouse motoneurons exhibit bursts of spontaneous electrical activity during motor axon outgrowth (Milner and Landmesser, 1999; Hanson and Landmesser, 2003) and interfering with such activity perturbed motoneuron pathfinding (Hanson and Landmesser, 2004, 2006). In addition, aspects of synapse formation and maturation have been shown to be dependent on transmitter release, as they are altered in mice lacking choline acetyltransferase and thus the ability to make ACh (Misgeld et al., 2002; Brandon et al., 2003). Thus stimulus dependent release of $\mathrm{ACh}$ and other peptide/trophic factors clearly occurs, and given the presence of multiple types of ACh receptors on motor axons, growth cones and muscle fibers, such release could modulate diverse aspects of neuromuscular development. As an example, it was recently shown that ACh acting via Cdk 5 destabilizes AChR clusters that are not apposed by a pre- synaptic nerve terminal because these are not stabilized by agrin released by the motoneuron (Lin et al., 2005).

In vertebrates at both central synapses (Scheiffele et al., 2000; Biederer et al., 2002; Bamji et al., 2003; Kalinovsky and Scheiffele, 2004; Regalado et al., 2006) and NMJs (Dai and Peng, 1996; Liou and $\mathrm{Fu}, 1997$; Je et al., 2006) molecules have been identified that mediate retrograde signals that are required for different aspects of presynaptic differentiation. The failure of immature vesicle cycling to be downregulated at NMJs that lack all NCAM isoforms (Polo-Parada et al., 2001) and the synaptic transmission failures in NMJs lacking only the 180 isoform (Polo-Parada et al., 2004) clearly show that different NCAM isoforms also mediate distinct aspects of presynaptic maturation. To further elucidate the function of these isoforms and whether they were acting presynaptically or postsynaptically, first required a characterization of their distribution before and after myotube contact/synapse formation.

We have shown here that before contact motor axons have numerous puncta along the axon that contain both the 140 and 180 isoforms and that these are sites of stimulus dependent synaptic vesicle cycling. However it is unlikely that either isoform of NCAM is required for stimulus dependent synaptic vesicle cycling at these puncta, because the immature form of synaptic vesicle cycling persists at sites along preterminal axons in adult motoneurons in mice deficient in all isoforms of NCAM (PoloParada et al., 2001). However these two transmembrane isoforms of NCAM may be recruited to these sites, which contain numerous other molecules involved in transmitter release and vesicle exocytosis and endocytosis, via interactions with intracellular domains common to both isoforms, and play a later role in synaptic maturation as the puncta are recruited to the synapse. In cultured hippocampal neurons, exogenously expressed 180 NCAM and associated Trans-Golgi network-derived organelles accumulate at nascent synapses (Sytnyk et al., 2002) and have been proposed to stabilize developing contacts via homophilic NCAM binding (Sytnyk et al., 2004).

The present study also demonstrated that postsynaptic NCAM was required for the presynaptic 140 isoform to be targeted to the synapse. It is thus possible that direct homophilic binding between 140 NCAM on the myotube and on the presynaptic terminal mediates this process. At early stages of chick and mouse myotube formation in vivo and in culture (Covault et al., 1986; Moore et al., 1987; Fredette et al., 1993; Rafuse and Landmesser, 1996), and when synapses first form in vivo (Dahm and Landmesser, 1991) the muscle-specific form of the 140 isoform, which runs on gels at $145 \mathrm{kDa}$, is the predominant isoform on myotubes. Only after synapses form and the muscle is electrically activated in vivo (Fredette et al., 1993) or after myotubes become spontaneously active in culture (Rafuse and Landmesser, 1996) does an activity dependent switch in the predominant isoform from the $145 \mathrm{kDa}$ to the GPI-linked 120 isoform, which runs at $125 \mathrm{kDa}$ in muscle, occur. Thus it is very likely that the 140 isoform on myotubes is responsible for the selective presynaptic targeting of the neuronal 140 isoform.

In contrast, the presynaptic 180 isoform did not require postsynaptic NCAM for synaptic targeting. Because the extracellular domains of the 140 and 180 isoforms are essentially identical, synaptic targeting of the 180 isoform most likely occurs via interactions between domains within the 180-specific intracellular region and other presynaptic molecules. Recent studies have reported molecules that associate with the intracellular domains of either the 140 or 180 intracellular domains (Buttner et al., 2003, 2005), with $\beta$ actin, Map1A and ROK $\alpha$ selectively associ- 
ating with the 180 isoform. Furthermore, although both the 180 and 140 isoforms can associate with spectrin (Leshchyns'ka et al., 2003) dimeric spectrin, the predominant form in the CNS, preferentially associates with the 180 isoform (Pollerberg et al., 1987). Finally when $\alpha$ - or $\beta$-spectrin was mutated, selective presynaptic targeting of proteins involved in synaptic transmission such as cysteine string protein, synapsin and syntaxin was impaired at Drosophila neuromuscular junctions as was functional transmission (Featherstone et al., 2001). Whether interactions with spectrin or other as yet unidentified binding partners for the 180 specific intracellular portion of NCAM account for the selective presynaptic 180 isoform targeting we observed remain to be determined.

In summary, we have demonstrated that myotube contact provides a signal that results in the selective presynaptic targeting of 140 and 180 isoforms of NCAM and the concomitant switch from immature vesicle cycling along the axon to mature vesicle cycling targeted to the presynaptic terminal. We also showed that postsynaptic NCAM, most likely the 140 isoform, was required for the presynaptic targeting of the 140 isoform. Although many details of the isoform interactions that mediate these events as well as those responsible for the targeting of presynaptic 180 NCAM independent of postsynaptic NCAM remain to be elucidated, the culture system developed in this study should facilitate such observations.

\section{References}

Antonov I, Chang S, Zakharenko S, Popov SV (1999) Distribution of neurotransmitter secretion in growing axons. Neuroscience 90:975-984.

Bamji SX, Shimazu K, Kimes N, Huelsken J, Birchmeier W, Lu B, Reichardt LF (2003) Role of beta-catenin in synaptic vesicle localization and presynaptic assembly. Neuron 40:719-731.

Barbas JA, Chaix JC, Steinmetz M, Goridis C (1988) Differential splicing and alternative polyadenylation generates distinct NCAM transcripts and proteins in the mouse. EMBO J 7:625-632.

Betz WJ, Mao F, Smith CB (1996) Imaging exocytosis and endocytosis. Curr Opin Neurobiol 6:365-371.

Biederer T, Sara Y, Mozhayeva M, Atasoy D, Liu X, Kavalali ET, Sudhof TC (2002) SynCAM, a synaptic adhesion molecule that drives synapse assembly. Science 297:1525-1531.

Bixby JL, Baerwald-De la Torre K, Wang C, Rathjen FG, Ruegg MA (2002) A neuronal inhibitory domain in the $\mathrm{N}$-terminal half of agrin. J Neurobiol 50:164-179.

Bonnot A, Mentis GZ, Skoch J, O'Donovan MJ (2005) Electroporation loading of calcium-sensitive dyes into the CNS. J Neurophysiol 93:1793-1808.

Brandon EP, Lin W, D'Amour KA, Pizzo DP, Dominguez B, Sugiura Y, Thode S, Ko CP, Thal LJ, Gage FH, Lee KF (2003) Aberrant patterning of neuromuscular synapses in choline acetyltransferase-deficient mice. J Neurosci 23:539-549.

Buttner B, Kannicht C, Reutter W, Horstkorte R (2003) The neural cell adhesion molecule is associated with major components of the cytoskeleton. Biochem Biophys Res Commun 310:967-971.

Buttner B, Kannicht C, Reutter W, Horstkorte R (2005) Novel cytosolic binding partners of the neural cell adhesion molecule: mapping the binding domains of PLC $\gamma$, LANP, TOAD-64, syndapin, PP1 and PP2A. Biochemistry 44:6938-6947.

Chow I, Poo MM (1985) Release of acetylcholine from embryonic neurons upon contact with muscle cell. J Neurosci 5:1076-1082.

Covault J, Merlie JP, Goridis C, Sanes JR (1986) Molecular forms of N-CAM and its RNA in developing and denervated skeletal muscle. J Cell Biol 102:731-739.

Crossin KL, Krushel LA (2000) Cellular signaling by neural cell adhesion molecules of the immunoglobulin superfamily. Dev Dyn 218:260-279.

Cunningham BA, Hemperly JJ, Murray BA, Prediger EA, Brackenbury R, Edelman GM (1987) Neural cell adhesion molecule: structure, immunoglobulin-like domains, cell surface modulation, and alternative RNA splicing. Science 236:799-806.

Dahm LM, Landmesser LT (1991) The regulation of synaptogenesis during normal development and following activity blockade. J Neurosci 11:238-255.

Dai Z, Peng HB (1996) Dynamics of synaptic vesicles in cultured spinal cord neurons in relationship to synaptogenesis. Mol Cell Neurosci 7:443-452.

DiGregorio DA, Negrete O, Jeromin A, Peng HB, Vergara JL (2001) Contact-dependent aggregation of functional $\mathrm{Ca}^{2+}$ channels, synaptic vesicles and postsynaptic receptors in active zones of a neuromuscular junction. Eur J Neurosci 14:533-546.

Faundez V, Horng JT, Kelly RB (1998) A function for the AP3 coat complex in synaptic vesicle formation from endosomes. Cell 93:423-432.

Featherstone DE, Davis WS, Dubreuil RR, Broadie K (2001) Drosophila $\alpha$ and $\beta$-spectrin mutations disrupt presynaptic neurostransmitter release. J Neurosci 21:4215-4224.

Fredette B, Rutishauser U, Landmesser L (1993) Regulation and activitydependence of N-cadherin, NCAM isoforms and polysialic acid on chick myotubes during development. J Cell Biol 123:1867-1888.

Hanson MG, Landmesser LT (2003) Characterization of the circuits that generate spontaneous episodes of activity in the early embryonic mouse spinal cord. J Neurosci 23:587-600.

Hanson MG, Landmesser LT (2004) Normal patterns of spontaneous activity are required for correct motor axon guidance and the expression of specific guidance molecules. Neuron 43:687-701.

Hanson MG, Landmesser LT (2006) Increasing the frequency of spontaneous rhythmic activity disrupts pool-specific axon fasciculation and pathfinding of embryonic spinal motoneurons. J Neurosci 26:12769-12780.

Hartmann U, Vens C, Vopper G, Wille W, Heinlein UA (1994) Ectopic expression of NCAM in mouse fibroblasts stimulates self-aggregation, and promotes integration into primary cerebellum cell aggregates. Cell Adhes Commun 2:287-298.

Hong SJ, Chang CC (1995) Inhibition of acetylcholine release from mouse motor nerve by a P-type calcium channel blocker, omega-agatoxin IVA. J Physiol (Lond) 482:283-290.

Je HS, Yang F, Zhou J, Lu B (2006) Neurotrophin 3 induces structural and functional modification of synapses through distinct molecular mechanisms. J Cell Biol 175:1029-1042.

Jevsek M, Jaworski A, Polo-Parada L, Kim N, Fan J, Landmesser LT, Burden SJ (2006) CD24 is expressed by myofiber synaptic nuclei and regulates synaptic transmission. Proc Natl Acad Sci USA 103:6374-6379.

Kalinovsky A, Scheiffele P (2004) Transcriptional control of synaptic differentiation by retrograde signals. Curr Opin Neurobiol 14:272-279.

Kiss JZ, Muller D (2001) Contribution of the neural cell adhesion molecule to neuronal and synaptic plasticity. Rev Neurosci 12:297-310.

Krueger SR, Kolar A, Fitzsimonds RM (2003) The presynaptic release apparatus is functional in the absence of dendritic contact and highly mobile within isolated axons. Neuron 40:945-957.

Leshchyn'ka I, Sytnyk V, Morrow JS, Schachner M (2003) Neural cell adhesion molecule (NCAM) association with PKC $\beta 2$ via spectrin $\beta 1$ is implicated in NCAM mediated neurite outgrowth. J Cell Biol 161:625-639.

Lin W, Dominguez B, Yang J, Aryal P, Brandon EP, Gage FH, Lee KF (2005) Neurotransmitter acetylcholine negatively regulates neuromuscular synapse formation by a Cdk5-dependent mechanism. Neuron 46:569-579.

Liou JC, Fu WM (1997) Regulation of quantal secretion from developing motoneurons by postsynaptic activity-dependent release of NT-3. J Neurosci 17:2459-2468.

Matteoli M, Takei K, Perin MS, Sudhof TC, De Camilli P (1992) Exoendocytotic recycling of synaptic vesicles in developing processes of cultured hippocampal neurons. J Cell Biol 117:849-861.

Milner LD, Landmesser LT (1999) Cholinergic and GABAergic inputs drive patterned spontaneous motoneuron activity before target contact. J Neurosci 19:3007-3022.

Misgeld T, Burgess RW, Lewis RM, Cunningham JM, Lichtman JW, Sanes JR (2002) Roles of neurotransmitter in synapse formation: development of neuromuscular junctions lacking choline acetyltransferase. Neuron 36:635-648.

Moore SE, Thompson J, Kirkness V, Dickson JG, Walsh FS (1987) Skeletal muscle neural cell adhesion molecule (NCAM): changes in protein and mRNA species during myogenesis of muscle cell lines. J Cell Biol 105:1377-1386.

Pollerberg GE, Burridge K, Krebs KE, Goodman SR, Schachner M (1987) The $180-\mathrm{kD}$ component of the neural cell adhesion molecule NCAM is involved in cell-cell contacts and cytoskeleton-membrane interactions. Cell Tissue Res 250:227-236. 
Polo-Parada L, Bose CM, Landmesser LT (2001) Alterations in transmission, vesicle dynamics, and transmitter release machinery at NCAMdeficient neuromuscular junctions. Neuron 32:815-828.

Polo-Parada L, Bose CM, Plattner F, Landmesser LT (2004) Distinct roles of different neural cell adhesion molecule (NCAM) isoforms in synaptic maturation revealed by analysis of NCAM $180 \mathrm{kDa}$ isoform-deficient mice. J Neurosci 24:1852-1864.

Polo-Parada L, Plattner F, Bose C, Landmesser LT (2005) NCAM 180 acting via a conserved C-terminal domain and MLCK is essential for effective transmission with repetitive stimulation. Neuron 46:917-931.

Pyle JL, Kavalali ET, Choi S, Tsien RW (1999) Visualization of synaptic activity in hippocampal slices with FM1-43 enabled by fluorescence quenching. Neuron 24:803-808.

Rafuse VF, Landmesser L (1996) Contractile activity regulates isoform expression and polysialylation of NCAM in cultured myotubes: involvement of $\mathrm{Ca}^{2+}$ and protein kinase C. J Cell Biol 132:969-983.

Rando TA, Blau HM (1994) Primary mouse myoblast purification, characterization and transplantation for cell-mediated gene therapy. J Cell Biol 125:1275-1287.

Regalado MP, Terry-Lorenzo RT, Waites CL, Garner CC, Malenka RC (2006) Transsynaptic signaling by postsynaptic synapse-associated protein 97. J Neurosci 26:2343-2357.

Rougon G, Hobert O (2003) New insights into the diversity and function of neuronal immunoglobulin superfamily molecules. Annu Rev Neurosci 26:207-238

Sabo SL, McAllister AK (2003) Mobility and cycling of synaptic proteincontaining vesicles in axonal growth cone filopodia. Nat Neurosci 6:1264-1269.

Sabo SL, Gomes RA, McAllister AK (2006) Formation of presynaptic terminals at predefined sites along axons. J Neurosci 26:10813-10825.

Sand O, Chen BM, Grinnell AD (2001) Contribution of L-type $\mathrm{Ca}^{2+}$ channels to evoked transmitter release in cultured Xenopus nerve-muscle synapses. J Physiol (Lond) 536:21-33.

Scheiffele P, Fan J, Choih J, Fetter R, Serafini T (2000) Neuroligin expressed in nonneuronal cells triggers presynaptic development in contacting axons. Cell 101:657-669.
Schlosshauer B (1989) Purification of neuronal cell surface proteins and generation of epitope-specific monoclonal antibodies against cell adhesion molecules. J Neurochem 52:82-92.

Storms SD, Kim AC, Tran BH, Cole GJ, Murray BA (1996) NCAMmediated adhesion of transfected cells to agrin. Cell Adhes Commun 3:497-509.

Sugiura Y, Ko CP (1997) Novel modulatory effect of L-type calcium channels at newly formed neuromuscular junctions. J Neurosci 17:1101-1111.

Sun YA, Poo MM (1987) Evoked release of acetylcholine from the growing embryonic neuron. Proc Natl Acad Sci USA 84:2540-2544.

Sundgren-Andersson AK, Johansson S (1998) Calcium spikes and calcium currents in neurons from the medial preoptic nucleus of rat. Brain Res 783:194-209.

Sytnyk V, Leshchyns'ka I, Delling M, Dityateva G, Dityatev A, Schachner M (2002) Neural cell adhesion molecule promotes accumulation of TGN organelles at sites of neuron-to-neuron contacts. J Cell Biol 159:649-661.

Sytnyk V, Leshchyns'ka I, Dityatev A, Schachner M (2004) Trans-Golgi network delivery of synaptic proteins in synaptogenesis. J Cell Sci 117:381-388.

Tang J, Landmesser L, Rutishauser U (1992) Polysialic acid influences specific pathfinding by avian motoneurons. Neuron 8:1031-1044.

Verderio C, Coco S, Bacci A, Rossetto O, De Camilli P, Montecucco C, Matteoli M (1999) Tetanus toxin blocks the exocytosis of synaptic vesicles clustered at synapses but not of synaptic vesicles in isolated axons. J Neurosci 19:6723-6732.

Watanabe M, Frelinger III AL, Rutishauser U (1986) Topography of N-CAM structural and functional determinants. I. Classification of monoclonal antibody epitopes. J Cell Biol 103:1721-1727.

Zakharenko S, Chang S, O’Donoghue M, Popov SV (1999) Neurotransmitter secretion along growing nerve processes: comparison with synaptic vesicle exocytosis. J Cell Biol 144:507-518.

Zhai RG, Vardinon-Friedman H, Cases-Langhoff C, Becker B, Gundelfinger ED, Ziv NE, Garner CC (2001) Assembling the presynaptic active zone: a characterization of an active one precursor vesicle. Neuron 29:131-143. 